\title{
Development and Characterization of Calmodulin-Based Copolymeric Hydrogels
}

\author{
Christopher S. Fox, Hunter A. Berry, and Susan Pedigo*
}

Cite This: https://dx.doi.org/10.1021/acs.biomac.0c00043

Read Online

ABSTRACT: Recently, there has been growing interest in harnessing genetically engineered polymers to develop responsive biomaterials, such as hydrogels. Unlike their synthetic counterparts, genetically engineered polymers are produced without the use of toxic reagents and can easily be programmed to incorporate desirable hydrogel properties, including bioactivity, biodegradability, and monodispersity. Herein, we report the development of a copolymeric hydrogel that is based on the calcium-dependent protein, calmodulin ( CaM). For our system, CaM and M13, a CaM-binding peptide, were incorporated into genetically engineered polymers with intervening linkers containing cleavable sequences. Spectroscopic and multipleparticle tracking (MPT) studies demonstrate that these polymers self-assemble through calcium-stabilized, noncovalent crosslinking to form a soft viscoelastic material. MPT further revealed that gelation is concentration-dependent. Collagenase digests show that the protein polymers are selectively degraded through specific cleavage. The modularity and stimuli-responsiveness of this system suggest its potential as a flexible scaffold for biomedical applications.

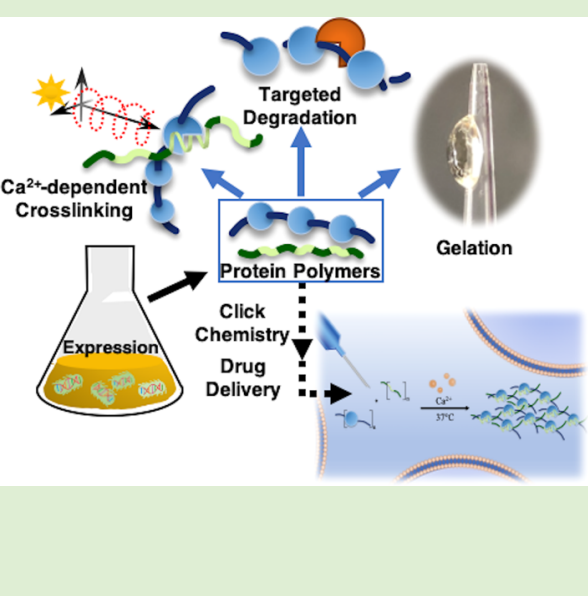

\section{INTRODUCTION}

Since they were first proposed for biological use in 1960, ${ }^{1}$ hydrogels have been studied and used extensively for numerous in vivo applications including wound dressing, ${ }^{2}$ controlled drug delivery, ${ }^{3-6}$ tissue engineering, ${ }^{7-11}$ and biological sensing. ${ }^{12-15}$ In short, hydrogels are defined as three-dimensional polymeric networks capable of retaining large amounts of water while maintaining their structure. This unique property is attributed to the hydrophilic nature of their constituent polymers, which normally range from naturally occurring polymers (e.g., polypeptides ${ }^{16-19}$ and polysaccharides $^{3,20-22}$ ) to chemically synthesized polymers (e.g., acrylamide, ${ }^{23,24}$ poly (vinyl alcohol), ${ }^{25-27}$ poly(ethylene glycol) $\left.(\mathrm{PEG})^{28-30}\right)$ and even hybrids of the two. ${ }^{31-34}$ In the last couple of decades, there has been increasing interest in exploiting protein engineering for the development of selfassembling hydrogels for biomedical applications due to the advantages of genetically engineered protein polymers. ${ }^{35-44}$ Various classes of genetically engineered polymers have been developed to form hydrogels, including silk-like polymers, ${ }^{45,46}$ silk-collagen polymers, ${ }^{47}$ elastin-like polymers (ELPs), ${ }^{48,49}$ silkelastin-like polymers, ${ }^{45,50}$ collagen-like copolymers, ${ }^{51,52}$ and leucine zipper copolymers. ${ }^{53}$ Broadly speaking, these classes are similar in that they all incorporate repetitions of specific sequence motifs derived from naturally occurring proteins to elicit noncovalent crosslinking through the formation of secondary or supersecondary structures (e.g., $\beta$-sheets, $\beta$ spirals, and $\alpha$-helical coiled-coils). In contrast, we have developed engineered protein polymers that form crosslinks through specific noncovalent interactions between two different components, calmodulin ( $\mathrm{CaM})$ and the CaM-binding peptide M13, that will assemble in response to the high concentration of extracellular calcium ions found in vivo.

Our two-component system consists of two genetically engineered proteins that have repetitions of either $\mathrm{CaM}$ or M13 separated by a linker segment. This CaM- and M13-based hydrogel system is represented schematically in Scheme 1. The

Scheme 1. Conceptual Schematic of Proposed Hydrogel Formation $^{a}$

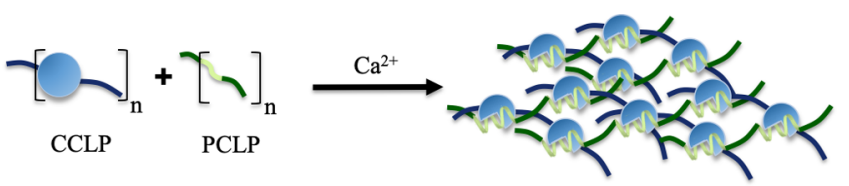

${ }^{a}$ Studies here report the characterization of the repeating $(n=3)$ CaM-block (blue circle) and M13-block polymers (green line) that interact in the presence of calcium to form a physically crosslinked hydrogel material (shown on the right).

Received: January 10, 2020

Revised: April 9, 2020 
amino acid sequence of both polymers can be seen in the Supporting Figure S1. The CaM-based polymer consists of three repeats of $\mathrm{CaM}$ with intervening 20-residue linker segments that contain one collagen-derived sequence (GPQGIWGQ), which is sensitive to cleavage by matrix metalloproteinases (MMPs) known as collagenases. The M13based polymer consists of three repeats of M13 with the same 20 -residue linkers segments. We will refer to these polymers as calmodulin collagen-like polymers (CCLP3) and peptide collagen-like polymers (PCLP3). CaM was chosen due to its specific, calcium-dependent, high-affinity interaction with M13 and its remarkable resilience to denaturants ${ }^{54,55}$ and high temperatures. ${ }^{56} \mathrm{CaM}$ is a well-studied, intracellular calcium signaling protein with two globular domains connected by a flexible central helix. ${ }^{57}$ The $\mathrm{C}$ - and N-terminal domains both contain a pair of EF-hand motifs that bind calcium and then M13 in an ordered series of events; calcium binds with $K_{d}<10$ $\mu \mathrm{M},{ }^{58-60}$ inducing exposure of the hydrophobic pocket in each domain; then, these hydrophobic pockets bind to M13 $\left(K_{\mathrm{d}}=\right.$ $10 \mathrm{nM})^{61}$ to form a specific, high-affinity complex. Since CaM and M13 bind each other under typical extracellular conditions, we expected that mixtures of hydrophilic CaMbased and M13-based polymers would lead to the formation of a hydrogel. Our two-component system was designed to be easily tunable by modifying the sequence of CaM, M13, or the linker segment, to self-assemble in situ within the extracellular space where free calcium ion concentrations are tightly regulated between 1.1 and $1.5 \mathrm{mM}^{62-64}$ and to be susceptible to endogenous extracellular proteases for targeted degradation for applications such as in situ drug delivery. ${ }^{3-6}$

Due to CaM's unique properties and structure, it has attracted interest in engineered protein-based systems. CaMbased fusion proteins have been developed as intracellular calcium sensors (c.f. ${ }^{65-67}$ ), as calcium-activated hydrogel switches for microfluidic devices, ${ }^{68}$ and as sponge-like hydrogel delivery systems for bioactive agents. ${ }^{69-73}$ Since these technologies either measure or require fluxes in calcium levels to function, their application is not appropriate in the extracellular matrix where calcium concentration is consistently maintained within a narrow range. However, there are two reports known to us of CaM-based materials that exploit the extracellular calcium levels for stabilization. Topp et al. reported a CaM-based "toolkit" comprising polymers with multiple components, including CaM-binding peptides, a peptide that forms a helical bundle, and a segment of PEG. ${ }^{74}$ Another interesting application of $\mathrm{CaM}$ in a novel biomaterial is a self-assembling particle that is made from CaM-ELP polymers, ${ }^{75}$ in which calcium leads to particle assembly.

Our hydrogel system is unique compared to the other CaMbased hydrogel materials in several ways. First, our system consists of polymers that are entirely encoded on a genetic level, whereas other CaM-based hydrogels are chemically synthesized through reactions that require additional reagents and purification steps. ${ }^{68,69,74,76}$ Genetically encoded polymers have been reported to exhibit higher monodispersity and are easily programmable, providing increased control over polymer composition, solubility, and lifetime. ${ }^{41,45,49,77-83}$ Second, our copolymeric hydrogel self-assembles rapidly in response to calcium, a biologically relevant cue, and does not require the addition of crosslinking reagents (allylamine, acrylamide, bisacrylamide, acrylate, APS, TEMED) or photochemical initiators. Facile calcium-induced assembly of our material makes it potentially suitable for in situ formation in biomedical applications. Third, the binding of calcium elicits gel formation but would not be responsible for the function of the material, such as drug release. ${ }^{68}$ Finally, the incorporation of collagenlike sequences provides for degradation by endogenous collagenases whose abundance and activity are increased in chronic inflammation ${ }^{84-87}$ and cancer. ${ }^{88-92}$

Herein, we submit the first report of a new CaM-based hydrogel that is designed to exploit the high extracellular calcium concentration to form physical crosslinks between the component polymers. The goal of this work is to establish the utility of the hydrogel design by characterizing the fundamental properties of the material. We began our investigation by first elucidating the properties of the component polymers, which include the CaM-M13 interactions, targeted degradation, and rheology. In addition, the polymers were subsequently mixed and studied to characterize conditions for hydrogel formation, the hydrogel erosion profile under degradative and nondegradative conditions, hydrogel morphology, and rheological properties. These studies serve to establish this material's future potential as a flexible scaffold for biomedical applications.

\section{EXPERIMENTAL PROCEDURES}

Cloning, Expression, and Purification. The genes for the CaMbased (CCLP3) and M13-based (PCLP3) polymers each code for three repeats of CaM and M13, respectively, and a C-terminal Cys residue. The coding sequence for MMP cleavage sites was engineered into all genes after each CaM or M13 sequence (GPQG/IWGQ). CCLP3 and PCLP3 genes were synthesized, cloned into pET-28a (+) vectors via $\mathrm{NdeI} / \mathrm{SalI}$ or $\mathrm{NdeI} / \mathrm{Xhol}$ restriction sites, and sequenced to confirm their integrity (Genscript, Inc.). All genes were codon optimized for expression in Escherichia coli. BL21(DE3) and DH5 $\alpha$ competent cells (Novagen) were subsequently transformed with the expression vectors using a standard protocol and stored at $-80{ }^{\circ} \mathrm{C}$ as $18 \%$ glycerol stocks.

CCLP3 and PCLP3 polymers were expressed and purified from BL21(DE3) expression cells using standard protocols ${ }^{93}$ with the following exceptions. Cell cultures were grown in lysogeny broth containing $2 \% \mathrm{w} / \mathrm{v}$ tryptone, $1 \% \mathrm{w} / \mathrm{v}$ yeast, and $1 \% \mathrm{w} / \mathrm{v} \mathrm{NaCl}$. After cells were grown on agar plates, a starter culture was inoculated with a single colony and incubated $\left(37^{\circ} \mathrm{C}\right.$ at $\left.250 \mathrm{rpm}\right)$ until the $\mathrm{OD}_{600}$ was $\sim 0.6$ AU. Large 1-L expression cell cultures were inoculated with 5 $\mathrm{mL}$ of starter culture and incubated until 0.6-0.8. For CCLP3 transformants, the expression cultures were then induced with 0.8 $\mathrm{mM}$ isopropyl thiogalactoside (IPTG) and allowed to express for an additional $5 \mathrm{~h}$ at $37^{\circ} \mathrm{C}$ at $250 \mathrm{rpm}$. Alternatively, expression cultures with PCLP3 transformants were removed from the incubator when $\mathrm{OD}_{600}$ was $0.6-0.8$, induced with $0.8 \mathrm{mM}$ IPTG, and then expressed at room temperature at $250 \mathrm{rpm}$ for $18 \mathrm{~h}$. After the cells were lysed, CCLP3 was in the soluble fraction but PCLP3 in the insoluble fraction.

For CCLP3 purification, the supernatant was heated to $80{ }^{\circ} \mathrm{C}$ for $10 \mathrm{~min}$ in the presence of $50 \mathrm{mM} \mathrm{CaCl}$, centrifuged, and the supernatant was dialyzed against $20 \mathrm{mM}$ Tris, $50 \mathrm{mM} \mathrm{CaCl}, 1 \mathrm{mM}$ DTT, and $\mathrm{pH} 7.4$ (binding buffer). The dialyzed samples were then loaded onto phenyl sepharose (GE Healthcare) ${ }^{94}$ The stationary phase was washed with 3 column volumes of binding buffer, followed by 3 column volumes of wash buffer $(20 \mathrm{mM}$ Tris, $50 \mathrm{mM} \mathrm{CaCl} 2,0.5$ $\mathrm{M} \mathrm{NaCl}, 1 \mathrm{mM}$ DTT, pH 7.4). CCLP3 was then eluted with $10 \mathrm{mM}$ ethylenediaminetetraacetic acid (EDTA), $200 \mathrm{mM}$ Tris, and pH 7.4. Fractions containing purified CCLP3 were dialyzed against deionized water, lyophilized, and stored as a dry powder at $-20^{\circ} \mathrm{C}$. For PCLP3 purification, the lysate pellet was washed three times with diluted Triton X-100 (ThermoFisher), centrifuged, and resuspended in denaturing HisTag chromatography buffer $(20 \mathrm{mM}$ Tris, $5 \mathrm{mM}$ imidazole, $6 \mathrm{M}$ urea, $\mathrm{pH}$ 7.9) and loaded onto a Ni-NTA resin (ThermoFisher) under denaturing conditions with imidazole-based 
competitive elution. The fractions containing purified PCLP3 were dialyzed against denaturing 4-(2-hydroxyethyl)-1-piperazineethanesulfonic acid buffer (10 mM HEPES, $140 \mathrm{mM} \mathrm{NaCl}, 6 \mathrm{M}$ urea, $\mathrm{pH}$ 7.4) and stored at $-20{ }^{\circ} \mathrm{C}$. The purity of the protein stocks was assessed using sodium dodecyl sulfate polyacrylamide gel electrophoresis (SDS-PAGE) stained with Coomassie blue. The concentrations of CCLP3 and PCLP3 were determined using calculated extinction coefficients, ${ }^{95} 32430$ and $35420 \mathrm{M}^{-1} \mathrm{~cm}^{-1}$, respectively. The molecular weights of the polymers were confirmed by matrixassisted laser desorption ionization time-of-flight mass spectrometry (MALDI-TOF MS) (Voyager-DE, Perspective Biosystems) using a sinapinic acid matrix.

Circular Dichroism. Calcium binding and protein-protein interactions were monitored by the change in the circular dichroism (CD) signal using an AVIV 202SF CD spectrometer. Polymer samples $(20 \mu \mathrm{M})$ were dissolved in HEPES buffer $(10 \mathrm{mM}$ HEPES, $140 \mathrm{mM} \mathrm{NaCl}, \mathrm{pH}$ 7.4) containing $3 \mathrm{M}$ urea. Exceptions are noted in figure legends. Circular dichroism (CD) spectra were acquired from 200 to $300 \mathrm{~nm}$ in $1 \mathrm{~nm}$ increments at $25^{\circ} \mathrm{C}$ with a $3 \mathrm{~s}$ averaging time. Each sample was scanned in triplicate. The path length of the cuvette was $0.1 \mathrm{~mm}$. Data were corrected for the buffer spectrum and then offset corrected.

Proteolysis of Collagen-Derived Sequences. The human matrix metalloproteinase-1 (MMP-1) (AnaSpec, Inc.) was selected to test degradation of the MMP-sensitive sequence by a specific interstitial human collagenase. MMP- 1 was activated by incubating at $37^{\circ} \mathrm{C}$ with $1 \mathrm{mM}$ 4-aminophenylmercuric acetate for $3 \mathrm{~h}$. Following activation, MMP-1 $(20 \mathrm{nM})$ was added to $50 \mu \mathrm{M}$ CCLP3 and incubated at $37{ }^{\circ} \mathrm{C}$. During digestion, $10 \mu \mathrm{L}$ samples were taken at 0 , 48 , and $72 \mathrm{~h}$. Proteolysis was quenched with the addition of 2X SDS reducing loading buffer, and samples were stored at $-20^{\circ} \mathrm{C}$. The cleavage products were then visualized using SDS-PAGE. No proteolytic digests were attempted for PCLP3, since the stock contains $6 \mathrm{M}$ urea, a condition that impairs enzyme function. For $\mathrm{pH}$ dependence studies, digests of CCLP3 were conducted using collagenase type I (Gibco), a crude isolate from Clostridium histolyticum containing a mixture of seven collagenases (weighing $68-130 \mathrm{kDa})$. CCLP3 solutions $(200 \mu \mathrm{M})$ were prepared at $\mathrm{pHs} 5.7$, 6.5, and 7.4 using 2-ethanesulfonic acid buffer (100 mM MES, 100 $\left.\mathrm{mM} \mathrm{NaCl}, 10 \mathrm{mM} \mathrm{CaCl}, 0.05 \% \mathrm{NaN}_{3}\right)$ and Tris buffer $(100 \mathrm{mM}$ Tris, $\left.100 \mathrm{mM} \mathrm{NaCl}, 10 \mathrm{mM} \mathrm{CaCl}_{2}, 0.05 \% \mathrm{NaN}_{3}\right)$. Collagenase $(0.02$ $\mathrm{mg} / \mathrm{mL}$ ) was incubated with the protein polymer solutions at $37{ }^{\circ} \mathrm{C}$ over a period of $21 \mathrm{~h}$, and $10 \mu \mathrm{L}$ samples were taken at various timepoints as noted in the figure legend. Proteolysis was quenched and the cleavage products were then visualized as described above. For the digest conducted at $\mathrm{pH}$ 5.4, enzymatic activity was undetectable (data not shown).

Hydrogel Formation. The general procedure for hydrogel formation was as follows: Solution A: lyophilized CCLP3 was resuspended in $10 \mathrm{mM}$ HEPES, $140 \mathrm{mM} \mathrm{NaCl}$, and $\mathrm{pH} 7.4$ at a desired concentration; Solution B: PCLP3 dissolved in denaturing HEPES buffer (10 mM HEPES, $140 \mathrm{mM} \mathrm{NaCl}, 6 \mathrm{M}$ urea, $\mathrm{pH} 7.4$ ) was concentrated, or diluted, to the desired concentration. To Solution $\mathrm{A}$, a small volume of $\mathrm{CaCl}_{2}$ and $\mathrm{NaN}_{3}$ was added and mixed by gently pipetting. This solution was then combined with a volume of Solution B to create a 1:1 molar ratio, mixed by gentle pipetting, and allowed to equilibrate at room temperature for approximately 20 min. Unless otherwise specified, the final concentrations of added calcium and $\mathrm{NaN}_{3}$, a bacteriostatic agent, were $20 \mathrm{mM}$ and $0.05 \%$ (w/ $\mathrm{v})$, respectively. To test the stabilizing effect of calcium ions on hydrogel formation, the following experiment was performed. Polymers were mixed (1:1 mole ratio) in microcentrifuge tubes to form hydrogels in the absence of added calcium; contaminating calcium ion concentration is $\sim 5 \mu \mathrm{M}$ as determined by atomic absorption spectroscopy. ${ }^{54,96}$ Calcium was added to one gel sample to a total concentration of $20 \mathrm{mM}$. The chelator EDTA was added to the other to a total of $5 \mathrm{mM}$ concentration to chelate the contaminating calcium ions. To test the effect of temperature on hydrogels, a sample of $18 \% \mathrm{w} / \mathrm{v}$ hydrogel was prepared at $25{ }^{\circ} \mathrm{C}$ in $20 \mathrm{mM} \mathrm{CaCl}$. The sample was subsequently placed in boiling water $\left(100^{\circ} \mathrm{C}\right)$ for $10 \mathrm{~min}$.
Hydrogel Erosion and Degradation. Erosion profiles of the hydrogel were determined spectroscopically. In a microcentrifuge tube, $50 \mu \mathrm{L}$ of hydrogels ( 9 and $18 \% \mathrm{w} / \mathrm{v}$ ) were formed as described above. To each hydrogel, $1 \mathrm{~mL}$ of erosion buffer (100 mM HEPES, $140 \mathrm{mM} \mathrm{NaCl}, 3 \mathrm{M}$ urea, $1 \mathrm{mM} \mathrm{CaCl}_{2}, 0.05 \% \mathrm{w} / \mathrm{v} \mathrm{NaN}$, $\mathrm{pH} 7.4$ ) was added and the samples were incubated at $37^{\circ} \mathrm{C}$. The $1 \mathrm{~mL}$ of erosion buffer was collected and replaced at specified timepoints over a period of $48 \mathrm{~h}$. The percent mass loss of protein was calculated by determining the summative mass of eroded protein in the overlying buffer, using the absorption at $280 \mathrm{~nm}$, and subsequently dividing by the total mass (the mass of protein that was calculated to be present in the hydrogels formed). Studies were done in triplicate.

Proteolytic degradation of 9 and $18 \% \mathrm{w} / \mathrm{v}$ hydrogels was also determined using the same procedure. To each hydrogel, $1 \mathrm{~mL}$ of degrading erosion buffer $(0.02 \mathrm{mg} / \mathrm{mL}$ collagenase, $100 \mathrm{mM}$ HEPES, $140 \mathrm{mM} \mathrm{NaCl}, 3 \mathrm{M}$ urea, $10 \mathrm{mM} \mathrm{CaCl} 2,0.05 \% \mathrm{w} / \mathrm{v} \mathrm{NaN}, \mathrm{pH} 7.4$ ) was added and the samples were incubated at $37^{\circ} \mathrm{C}$. The $1 \mathrm{~mL}$ of buffer was collected and replaced at specified timepoints over a period of $48 \mathrm{~h}$. Studies were done in triplicate.

Scanning Electron Microscopy. To assess the morphology of the hydrogel, samples were prepared and imaged with a scanning electron microscope (SEM). Using the general procedure described above, $10 \%(\mathrm{w} / \mathrm{v})$ hydrogels were formed in microfuge tubes, flashfrozen in liquid nitrogen, and then dehydrated by lyophilization under vacuum at $-5{ }^{\circ} \mathrm{C}$ for at least $24 \mathrm{~h}$. Lyophilized samples were then fractured using a razor to reveal the interior, mounted, sputtered with a thin layer $(\sim 10 \mathrm{~nm})$ of $\mathrm{Pt}$, and then imaged using traditional SEM JSM-7200 FLV FE-SEM in the School of Pharmacy Electron Microscopy Facility at the University of Mississippi.

Multiple-Particle Tracking (MPT). Particle tracking is a technique that utilizes micron-sized spherical tracers to probe the microstructure and even local or bulk rheological properties of the soft material in which they are embedded. ${ }^{97}$ This is done by tracking the thermally driven displacements of the colloidal particles in real time to obtain their ensemble-averaged mean square displacement (MSD), which can then be used to calculate the complex shear moduli (i.e., viscosity and shear moduli) of the medium. For our studies, a Leica SP8 confocal laser scanning microscope in the Department of Biological Sciences at the University of Mississippi, mounted on a Leica DMI 8 inverted microscope with $63 \times$ NA 1.40 and $40 \times$ NA 1.30 oil immersion objectives, was used to record the motion of $0.2,0.5,1.0$, and $2.0 \mu \mathrm{m}$ fluorescent carboxylate-modified polystyrene spheres (Molecular Probes, Inc.). The tracer particles were mixed with polymer samples at concentrations of $0.02-0.2 \mathrm{vol} \%$ $\left(\sim 10^{7}-10^{9}\right.$ particles $\left./ \mu \mathrm{L}\right)$ to ensure that at least 100 particles were tracked per frame. Sample volumes of $8 \mu \mathrm{L}$ were loaded into $120-\mu \mathrm{m}$ deep spacer wells (Invitrogen) between coverslips of $0.17 \mathrm{~mm}$ thickness and immediately sealed to prevent evaporation and drift. For hydrogels, tracers were added to each solution of polymer, which were then mixed in wells and allowed to equilibrate for $30 \mathrm{~min}$ before imaging. Tracers were excited at $510 \mathrm{~nm}$ using a white light laser, and their fluorescence was monitored at 520-570 nm. Field of view areas of $512 \times 256$ pixels $(158 \mu \mathrm{m} \times 79 \mu \mathrm{m})$ and $512 \times 512$ pixels $(158 \mu \mathrm{m}$ $\times 158 \mu \mathrm{m}$ ) were chosen to obtain a scan rate of 50 and $30 \mathrm{~Hz}$, respectively, using the resonant scanning mode. The optical section was optimized to monitor a single layer of microspheres with a lateral resolution of $155 \mathrm{~nm}$. Particle positions were recorded for $1-10 \mathrm{~min}$ yielding 3038-18300 frames. All videos were recorded at a depth of at least $20 \mu \mathrm{m}$ to minimize hydrodynamic interactions with the coverslip. Interactive Data Language (IDL, Harris Geospatial Solutions) routines developed by Crocker and Grier ${ }^{98}$ were used to trace particle trajectories, determine the MSDs, and extract viscosities. All MSD data points were required to include a sampling size of $\sim 1000$ displacement measurements to increase the statistical accuracy of the results. Routines in the IDL routines were not altered, however, parameters for locating features using the routines (e.g., bandpass filter, feature size, masscut/lower brightness cutoff) vary between samples. Each data set was optimized individually. The recorded videos were saved as tiff files, which are directly read into IDL. 
A

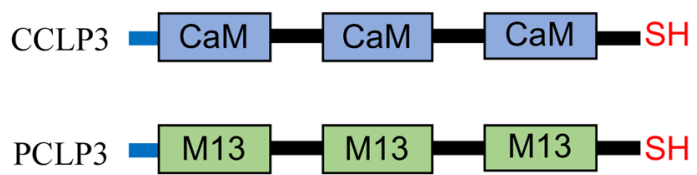

C

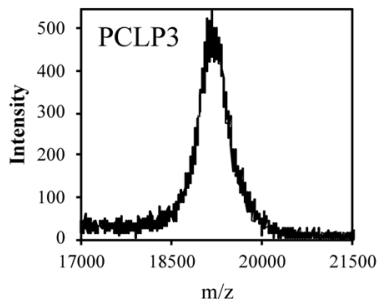

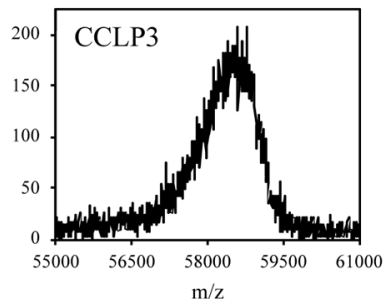

B

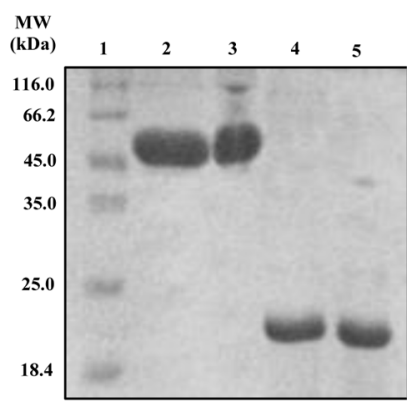

Figure 1. (A) Schematic of the CaM-based polymer CCLP3 (58 675 g/mol) and M13-based polymer PCLP3 (19 $307 \mathrm{~g} / \mathrm{mol})$. Each polymer has 3 repeats of the crosslinking components CaM (blue rectangle) or M13 (green rectangle) followed by a segment containing the MMP cleavage site (black bar). The N-terminal leader sequence (blue bar) contains a hexahistidine-tag for purification. The C-terminal cysteine is indicated by -SH; this thiol serves as a potential site for covalently attaching a desired moiety. (B) Reducing and nonreducing SDS-PAGE assay of purified polymers: lane 1, MW standard; lanes 2 and 3, reduced and nonreduced CCLP3, respectively; and lanes 4 and 5, reduced and nonreduced PCLP3, respectively. (C) Mass determination of polymers using MALDI-TOF MS analysis.

Prior to microrheology studies of the novel materials, MSDs of 0.5 and $1 \mu \mathrm{m}$ tracer particles in glycerol $(0-70 \% \mathrm{w} / \mathrm{w})$ were used to validate our MPT scheme (see Figures S2 and S3). The MSD, $\left\langle\Delta r^{2}(\tau)\right\rangle$, is a function of lag time, $\tau=n \Delta t$, where $\Delta t$ is the time interval between consecutive frames and $n$ is a positive integer. The shortest lag time possible $(\tau=\Delta t)$ is determined by the inverse of the frame rate in which the video is recorded, which is typically $30-100$ $\mathrm{Hz}$. The longest lag time is limited by the total duration of the video. In two dimensions, the MSD for an ensemble of particles is defined as

$$
\left\langle\Delta r^{2}(\tau)\right\rangle=\frac{1}{N} \sum_{i=1}^{N}\left\langle\left[x_{i}\left(t+\tau_{n}\right)-x_{i}(t)\right]^{2}+\left[y_{i}\left(t+\tau_{n}\right)-y_{i}(t)\right]^{2}\right\rangle
$$

where $x$ and $y$ represent the ith particle's positions. The brackets indicate a time-average over all start times $t$ for a single particle trajectory at a given lag time $\tau_{n}$, and $1 / N \sum_{i=1}^{N}$ represents the ensemble-average over all particle trajectories $N$ for each lag time observed. Thus, as lag time increases, the sample size of observed particle displacements decreases, thereby lowering the confidence in the calculated MSD. This statistical error was mitigated by increasing the number of measured displacements required to calculate an MSD data point for any given $\tau$. The double-logarithmic plot of MSD versus $\tau$ was fit to a power law, in which the data's slope, $\alpha$, qualitatively describes the rheological properties of a medium and is defined as

$$
\alpha=\frac{d \ln \left\langle\Delta r^{2}(\tau)\right\rangle}{d \ln \tau}
$$

For a purely viscous medium, such as aqueous glycerol, the $\log -\log$ plot of MSD versus lag time $\tau$ for an ensemble of thermally driven particles increases linearly with time, MSD $\sim \tau^{\alpha=1}$. Using the diffusion equation, the MSD can be related to the diffusion coefficient, $D$, by the following formula

$$
\left\langle\Delta r^{2}(\tau)\right\rangle=2 d D \tau
$$

where $d$ is the dimensionality of the displacements (2 for our studies). The viscosity of the material can then be calculated using the StokesEinstein equation

$$
\eta=\frac{k_{\mathrm{B}} T}{6 \pi a D}
$$

where $k_{\mathrm{B}}$ is Boltzmann's constant, $T$ is absolute temperature, and $a$ is the radius of the particle.
In contrast, particles embedded in a purely elastic medium will have constrained motion and their displacement will fluctuate around an equilibrium position, resulting in a constant MSD over time $(\alpha=0)$. Viscoelastic materials are more complex, possessing characteristics of both viscous and elastic materials, and are capable of both dissipating energy (viscous component) and storing energy (elastic component). The slope of a $\log -\log$ plot for viscoelastic materials falls in between the elastic and viscous limits $(0<\alpha<1)$, as observed in the materials under study here. A slope less than one suggests slow or subdiffusion within the medium and indicates an elastic response. Although the slope of the MSD plot can be used to describe the viscoelastic properties of a medium, the MSD can also be used to quantitate viscoelasticity in terms of the storage and loss moduli provided that the continuum requirement is met by the materials. For viscoelastic materials, a generalized Stokes-Einstein relation (GSER) ${ }^{99-102}$ can be used to determine the complex shear modulus, $G^{*}(\omega)$, which can then be related to the storage $G^{\prime}(\omega)$ and loss $G^{\prime \prime}(\omega)$ moduli. The GSER is defined in the Fourier domain as

$$
\begin{aligned}
& G^{*}(\omega)=\frac{k_{\mathrm{B}} T}{\pi a i \omega\left\langle\Delta r^{2}(i \omega)\right\rangle} \\
& G^{*}(\omega)=G^{\prime}(\omega)+i G^{\prime \prime}(\omega)
\end{aligned}
$$

where $i=\sqrt{-1}$, the angular frequency $\omega=2 \pi / \tau$, and $\left\langle\Delta r^{2}(i \omega)\right\rangle$ is the unilateral Fourier transform of the MSD. Since the Fourier transform requires an infinite range, and the MSD data only cover a limited range, implementation of this process can result in significant errors in $G^{*}(\omega)$ near the frequency extremes of the MSD data. To help circumvent such errors, a local power law expansion of the MSD around a desired frequency, $\omega$, that was developed by Mason et al., and improved upon by Dasgupta et al., can be used to derive algebraic estimates of the transforms. ${ }^{103,104}$ However, for the studies reported here, the MSD data were sufficient to describe the rheological properties of our material.

\section{RESULTS AND DISCUSSION}

Expression and Purification of CCLP3 and PCLP3. Figure 1A shows a schematic of the CCLP3 and PCLP3 polymers, so named due to three repeats of either CaM and M13, respectively; a thiol group is shown to depict the Cterminal cysteine, which was incorporated into the constructs as a potential site for specific covalent modification. Since these constructs are novel, standard expression and purification 
protocols were revised to optimize the level of expression as noted in experimental procedures. Expression yields for CCLP3 ( $\sim 100 \mathrm{mg} / \mathrm{L}$ of culture) were high compared to that of PCLP3, which only yielded $\sim 40 \mathrm{mg} / \mathrm{L}$ of culture. Figure $1 \mathrm{~B}$ shows a reducing and nonreducing SDS-PAGE assay of the purified constructs, indicating high purity and molecular weights predicted by their sequence. Nonreducing SDSPAGE further revealed that disulfide bond formation via the C-terminal cysteine for both CCLP3 and PCLP3 was negligible (see Figure 1B, lanes 3 and 5 ). The solubility of the CCLP3 polymer was high in water $(\geq 5 \mathrm{mM})$; however, the PCLP3 polymer required a denaturant to improve its solubility in aqueous buffers ( $\geq 5 \mathrm{mM}$ in $6 \mathrm{M}$ urea). Molecular weights of PCLP3 and CCLP3 were also determined experimentally using MALDI-TOF mass spectrometry (Figure 1C), which yielded masses of $19227 \mathrm{~g} / \mathrm{mol}$ (0.42\% difference) and $58575 \mathrm{~g} / \mathrm{mol}$ ( $0.17 \%$ difference), respectively, values nearly identical to those based on the amino acid sequences.

Calcium Binding of CCLP and Protein-Protein Interactions with PCLP. For our hydrogel system, calciumdependent hydrophobic interactions between complementary polymers are used to form physical crosslinks, which lead to the formation of the 3D hydrophilic network of the hydrogel. It is important to determine if the context of $\mathrm{CaM}$ within the polymer disrupts its ability to bind calcium or M13. Since CCLP3 contains repeats of CaM, we expected that the polymer should experience a conformational change upon binding calcium. ${ }^{105,106}$ To test the calcium and PCLP3 binding functionality of CCLP3, we first monitored the constructs in the presence (saturated) and absence (apo) of calcium using $\mathrm{CD}$ spectroscopy. These studies were performed at polymer concentrations well below the critical concentration required for gelation. Since PCLP3 has poor solubility in aqueous solvents, PCLP3 spectra were obtained in buffered solution containing $6 \mathrm{M}$ urea. The spectra of all other samples were acquired in HEPES buffered solutions with at least $3 \mathrm{M}$ urea to mimic the solution conditions under which the hydrogel would form. The results of these spectroscopic studies can be seen in Figure 2. As expected, PCLP3 appears disordered with no observable secondary structure. ${ }^{106,107}$ In contrast, apo-CCLP3

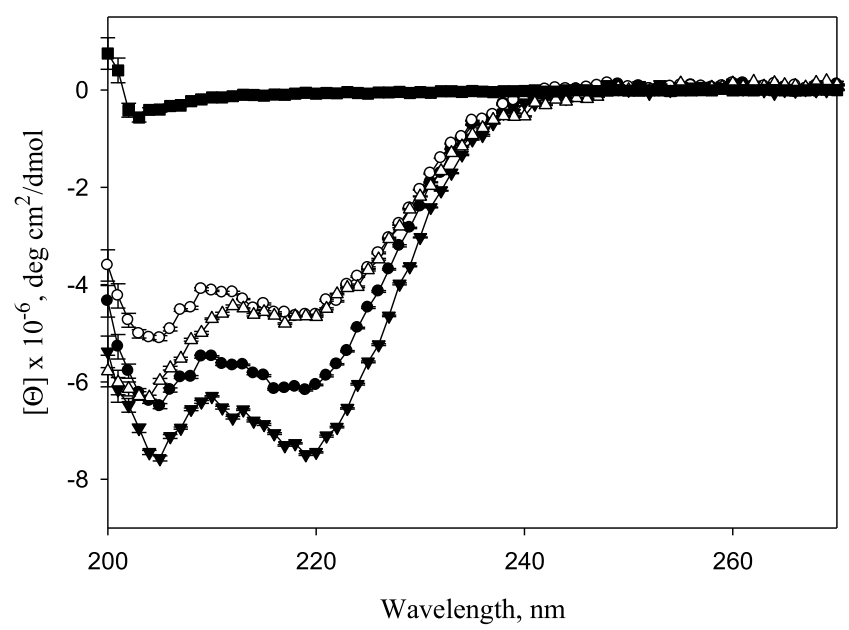

Figure 2. CD spectra of CCLP3 were taken in order starting with the apo state (O), Ca-saturated state $(\mathbf{O})$, addition of equimolar levels of PCLP3 to the saturated state of CCLP3 to create the ternary complex $(\boldsymbol{\nabla})$, and then the addition of EDTA to strip calcium from the ternary complex $(\triangle)$. A spectrum of PCLP3 taken in $6 \mathrm{M}$ urea is shown ( $\boldsymbol{\square})$. exhibited two minima at 220 and $205 \mathrm{~nm}$ that are characteristic of the $\alpha$-helical structure of $\mathrm{CaM},{ }^{108}$ which suggests that CaM is folded within the engineered polymer and in $3 \mathrm{M}$ urea. When calcium is added, an increase in CD signal is observed for CCLP3 as expected based on similar studies of CaM, ${ }^{108}$ thereby demonstrating that the calcium-binding sites in CaM are functional and undergo conformational change upon the binding of calcium. Calcium-saturated CCLP3 was then mixed with PCLP3 (1:1 molar ratio) to assess whether the polymers interact. Results show that there was significant conformational change as witnessed in the increased signal at 220 and $205 \mathrm{~nm}$ indicating CCLP3 binds PCLP3, consistent with the literature reports on CD spectra of isolated M13 and CaM constructs. ${ }^{106}$ These results indicate that CaM and M13 components of the respective polymers are functional and interact in solution.

To determine the reversibility of the protein polymer interactions, EDTA was added to samples containing calciumsaturated CCLP3 bound to PCLP3. The CD spectrum shown in Figure 2 confirms that when calcium is stripped from the mixture of CCLP3 and PCLP3, the spectrum reverts to the spectrum for apo-CaM for the minimum at $220 \mathrm{~nm}$. The signal at $205 \mathrm{~nm}$ is the sum of the signal of unstructured peptide and apo-CaM, as we would expect. This result attests to the role of calcium binding in promoting the association of polymers to form noncovalent crosslinks and the reversibility of the polymer interactions.

Targeted Degradation of Collagen-Derived Sequences. The second major functional aspect of the engineered polymers is the degradability of the collagen-derived sequence GPQGIWGQ, which is contained within the linker segments that separate the crosslinking sites. This specific sequence is a substrate for endogenous collagenases. ${ }^{109}$ The expected fragmentation of CCLP3 due to targeted cleavage by collagenases is shown in Scheme 2. Initial enzymatic cleavage

Scheme 2. Schematic of Peptide Map of CCLP3 ${ }^{a}$

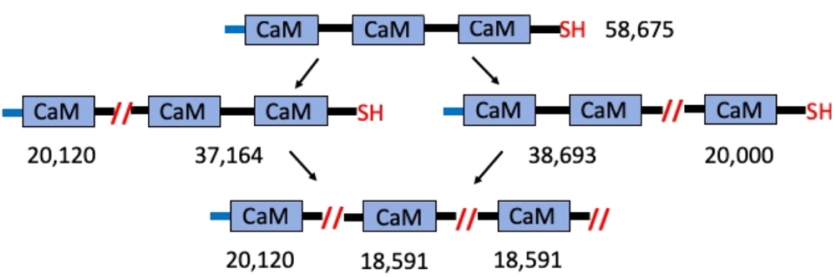

${ }^{a}$ Regardless of the initial cleavage, there are two similarly sized fragments formed. Subsequent cleavage of those two fragments will yield two terminal fragments at $\sim 20$ and $18 \mathrm{kDa}$ in a 1:2 ratio.

of CCLP3 creates a larger transient intermediate $(\sim 38 \mathrm{kDa}$; two CaM-linker repeats) and a single-repeat fragment $(\sim 20$ $\mathrm{kDa})$. Subsequent cleavage of the intermediate $38 \mathrm{kDa}$ fragment yields two final terminal products $(\sim 20$ and $\sim 18$ $\mathrm{kDa})$.

To test the susceptibility of the GPQGIWGQ sequence to collagenase, we first digested CCLP3 using human MMP-1, a protease associated with normal tissue remodeling, especially in chronic wounds. ${ }^{110-112}$ The SDS-PAGE assay of the digest products at $\mathrm{pH} 7.4$, shown in Figure 3, demonstrates that the cleavage products obtained using MMP-1 coincide with the predicted peptide map due to the activity of human MMP-1. After a $48 \mathrm{~h}$ digest, remaining full-length CCLP3 can be seen along with three additional bands, which correspond to the two-repeat transient intermediates $(\sim 38 \mathrm{KDa})$ and the two 


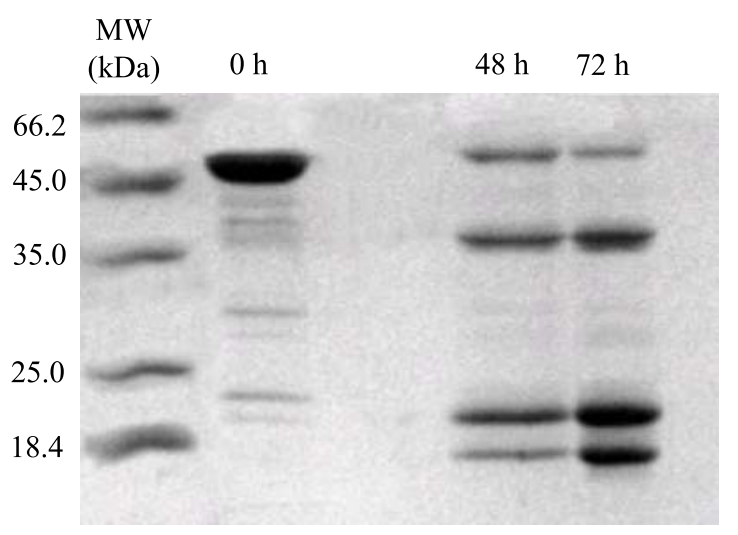

Figure 3. SDS-PAGE assay showing fragments from digestion of CCLP3 $(50 \mu \mathrm{M})$ after 0,48 , and $72 \mathrm{~h}$ in solutions containing $20 \mathrm{nM}$ MMP-1; collagen cleavage resulted in transient intermediate $(\sim 38$ $\mathrm{kDa})$ and terminal fragments $(\sim 20$ and $\sim 18 \mathrm{kDa})$, as predicted in Scheme 2 .

terminal fragments $(\sim 20$ and $\sim 18 \mathrm{kDa})$, which increase in abundance at a longer digest time.

The activity of collagenases is $\mathrm{pH}$-dependent; an increase in collagenase activity has been observed in acidified tissues during inflammation ${ }^{84,113,114}$ and cancer. ${ }^{115,116}$ To test the $\mathrm{pH}$ dependent cleavage of CCLP3, we performed collagenase digests at $\mathrm{pH} 7.4$ (Figure 4A) and 6.5 (Figure 4B) using a mixture of proteases isolated from $C$. histolyticum, the primary component of which is collagenase. ${ }^{117}$ In Figure $4 A, B$, the SDS-PAGE assay of the cleavage products of CCLP3 shows convergence on the single-repeat fragments as the time increases. Notice that the degradation of CCLP3 was

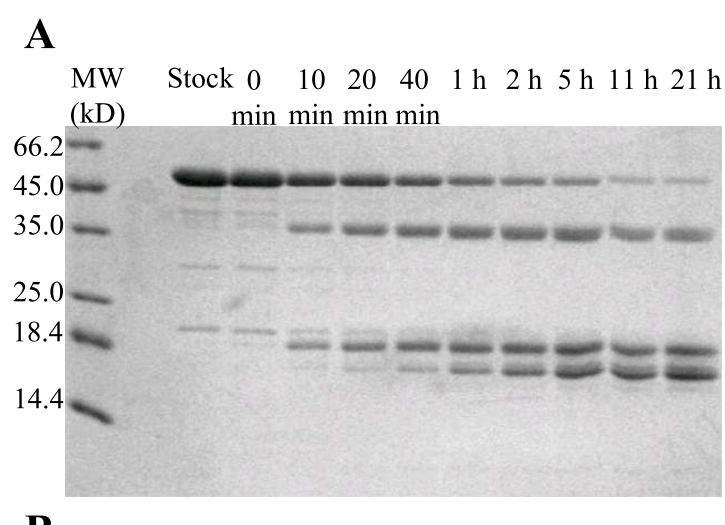

B

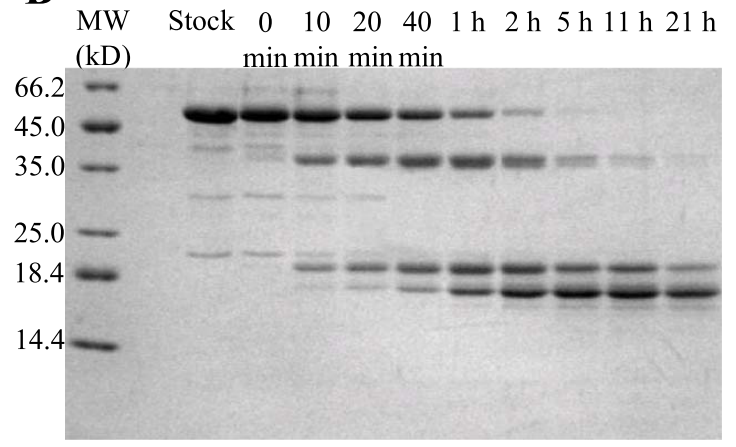

Figure 4. (A) SDS-PAGE assay of CCLP3 (stock) and collagenase digest of the polymer at $\mathrm{pH} 7.4$ with samples collected over a $21 \mathrm{~h}$ period. (B) SDS-PAGE of CCLP3 (stock) and digest of the polymer at $\mathrm{pH} 6.5$ with samples collected over $21 \mathrm{~h}$. significantly slower at $\mathrm{pH}$ 7.4. Full-length CCLP3 and the two-repeat fragment were both present after $21 \mathrm{~h}$ of digest at $\mathrm{pH}$ 7.4. However, a marked increase in collagenase activity was observed at $\mathrm{pH} 6.5$ (Figure 4B) such that digests of CCLP3 were virtually complete after only $11 \mathrm{~h}$. Thus, these digest data indicate that the actual cleavage pattern follows the predicted peptide map regardless of whether the collagenase activity is from a human or a pathogen. We observed increased activity of collagenase at the decreased $\mathrm{pH}$ level observed during chronic inflammation. ${ }^{84,113,114}$ These findings confirm that the chemistry of the engineered degradation sites is intact in these polymers since they are degraded by the targeted action of specific extracellular enzymes. The genetic origin of the polymers allows for tuning of their degradability by simply substituting new cleavage sites from a library of sequences with varying degrees of specificity and kinetics across a range of MMPs. ${ }^{118}$

Hydrogel Formation. To form hydrogels, solutions of CCLP3 and PCLP3 polymers were combined in a 1:1 molar ratio (CaM to M13) and mixed using a pipet to form $18 \% \mathrm{w} / \mathrm{v}$ hydrogels. The mixture immediately clouded, likely due to the decrease in the urea concentration and the generally poor solubility of PCLP3. The polymers were mixed by pipetting. By the third attempt draw into the pipettor, the mixture became too viscous to pipet. Over a period of $\sim 10 \mathrm{~min}$, the cloudiness dissipated creating the transparent hydrogels shown in Figure 5. This observation is likely a result of the slow increase in solubility of PCLP3 due to the formation of noncovalent crosslinks with CCLP3. The time frame of this process illustrates that the polymers are in motion in the gel and continue to optimize and establish crosslinks between polymers even after the gel has become too viscous to pipet. As is clear from the images of hydrogels in Figure 5, there is no excess solvent that pools outside of the hydrogel matrix. This observation was consistent for gels formed from total protein polymer concentrations ranging between 9 and $18 \% \mathrm{w} / \mathrm{v}$. Swelling experiments showed no evidence of swelling beyond the total volume of the mixed components (data not shown). Further, the nature of the hydrogels is such that they do not flow on vertical surfaces (Figure 5A). When gels were mechanically manipulated, they deformed and remained deformed, with only low levels of self-healing. This deformation is obvious for the hydrogels in the microfuge tubes shown in Figure 5B. These initial studies of gel formation indicated to us that there was significant and pervasive interaction between PCLP3 and CCLP3 in the mixtures leading to the formation of a regular, apparently homogeneous hydrogel.

Based on the equilibration time required for the incorporation of precipitated PCLP3 into the gel and the calcium requirement for high-affinity binding of M13 to CaM, we expected that there would be a calcium dependence to the character of the hydrogel that is formed. In Figure $5 \mathrm{C}$ is an image of two microcentrifuge tubes with $18 \% \mathrm{w} / \mathrm{v}$ hydrogels made with CCLP3 and PCLP3. The sample on the right is in the presence of calcium. The sample on the left has EDTA added to deplete the free calcium concentration ${ }^{119}$ to $<0.01 \times$ the $K_{\mathrm{d}}$ for calcium. ${ }^{58-60}$ The hydrogel on the left is cloudy indicating that there was precipitation of protein, presumably PCLP3, whose solubility is significantly lower in $3 \mathrm{M}$ urea if it is not crosslinked to CaM in the CCLP3 polymer. Observations from this experiment demonstrate the critical role of calcium in forming the noncovalent crosslinks between 

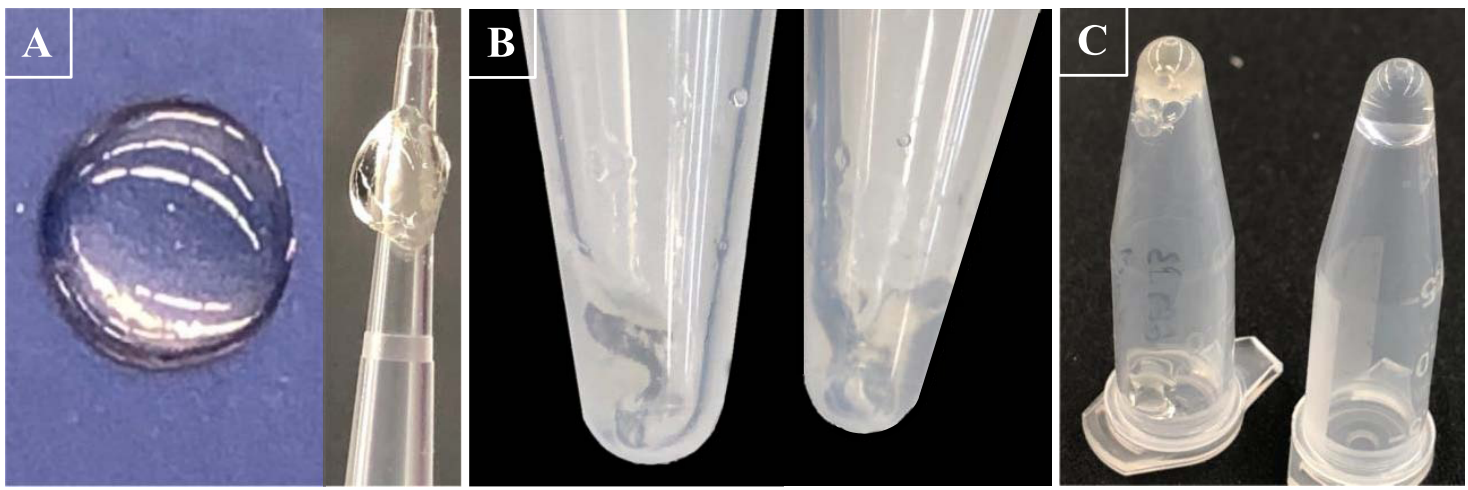

Figure 5. Images of $18 \% \mathrm{w} / \mathrm{v}$ hydrogels. (A) Hydrogel was formed on glass coverslips and removed with a pipet tip. (B) Hydrogels $(60 \mu \mathrm{L})$ were formed within a microcentrifuge tube and subsequently deformed using a pipet tip. (C) Hydrogels (18\%) were incubated in EDTA (left) or in added calcium (right).

component polymers, a result in agreement with the spectroscopic studies presented in Figure 2 and studies reported in the literature. ${ }^{106}$

The hydrogel is stable in boiling water, as illustrated in Figure 6 below. In this study, a 18\% w/v hydrogel was formed

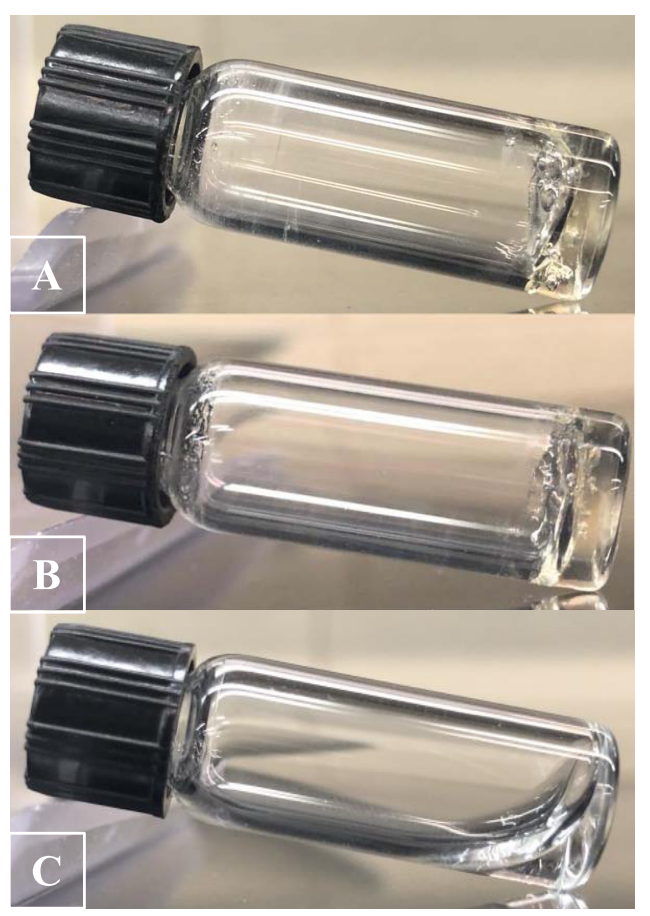

Figure 6. Hydrogel heat treatment; a $18 \% \mathrm{w} / \mathrm{v}$ hydrogel was formed in a vial (A) and subsequently boiled for $10 \mathrm{~min}(\mathrm{~B})$; water (C) is shown for comparison. Image (B) was taken immediately after boiling.

as described above, but in a small glass sample vial (Figure $6 \mathrm{~A}$ ). The irregular surface of the $18 \%$ hydrogel is due to air bubbles introduced upon pipetting highly concentrated protein solutions. Figure 6B shows the same vial immediately after placing it in boiling water for $10 \mathrm{~min}$. After the hot water treatment, the prominent air bubble on the gel surface was gone, but minor air bubbles were still present, and the surface of the boiled hydrogel had persistent irregularities, indicating that heating did not "heal" the surface. There was no pooled solution associated with the hydrogel. The hydrogel was a soft solid before and after heating.
These experiments demonstrate that the CCLP3 and PCLP3 polymers readily form a hydrogel that can accommodate large amounts of water in its matrix over the range of the total polymer concentration that we tested $(9-18 \% \mathrm{w} / \mathrm{v})$. Further, a $18 \%$ hydrogel is able to resist vertical flow without significant deformation, as witnessed in both sets of gelation experiments presented here. The PCLP3 polymer has low solubility in aqueous solutions unless it is crosslinked within the hydrogel network. We observed solubility issues when we initially mixed the polymers prior to hydrogel formation and again when the noncovalent crosslinking was destabilized by removing calcium ions with the addition of EDTA chelator. This "solubility" phenomenon allowed us to witness the ability of the hydrogels to optimize the interactions within the hydrogel over a $10 \mathrm{~min}$ period even after the gel was too viscous to pipet. This observation implies that this material can remodel itself on a molecular scale even if it retains deformations on a macroscopic scale. Interestingly, the gel matrix survives heat treatment at $100{ }^{\circ} \mathrm{C}$, an attribute that is likely due to the structural resilience of calcium-saturated $\mathrm{CaM},{ }^{55,56}$ making it reasonable to assume that these hydrogel materials could be sterilized for use in cell culture or in vivo.

Hydrogel Erosion and Degradation. Results from erosion studies of the hydrogel can be seen in Figure 7. Initial erosion rates for 9 and $18 \% \mathrm{w} / \mathrm{v}$ hydrogels were relatively high

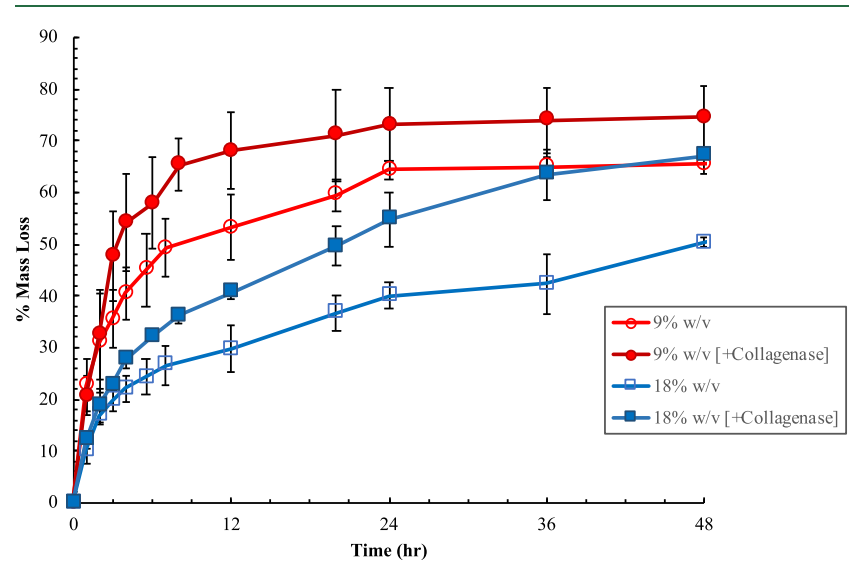

Figure 7. Erosion profiles of 9 and $18 \% \mathrm{w} / \mathrm{v}$ hydrogels with and without the addition of collagenase; the presence of collagenase accelerates the erosion of protein from the hydrogel material. Error bars represent standard deviations obtained from triplicate data. 


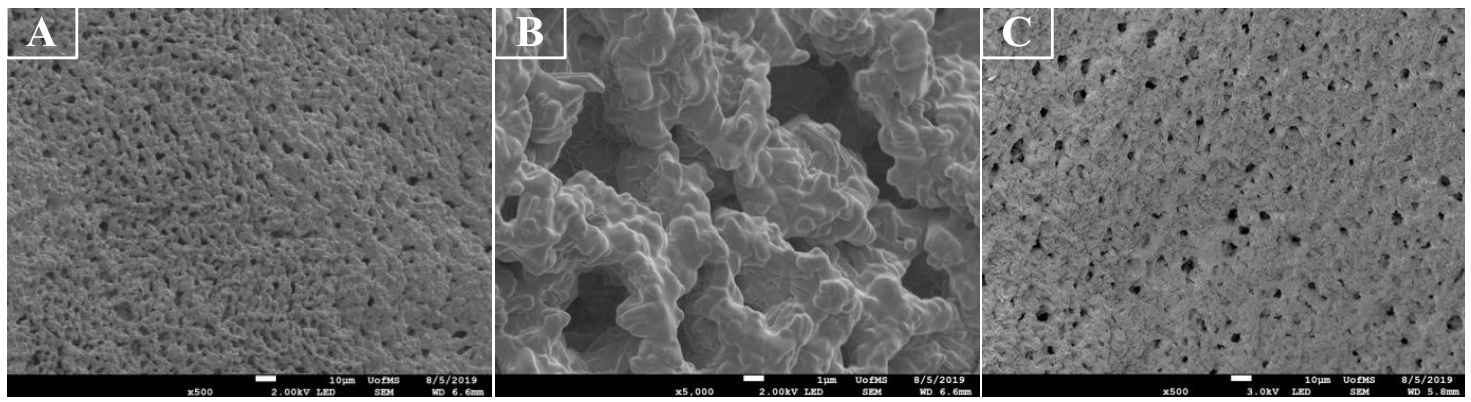

Figure 8. SEM micrographs depicting the morphology of a lyophilized $9 \% \mathrm{w} / \mathrm{v}$ hydrogel (1:1 molar ratio); (A) depicts the exterior of the sample; white bar is $10 \mu \mathrm{m}$. (B) $\sim 10 \times$ magnification of image (A) that shows a subset of pores at the surface; (C) shows the interior morphology of the hydrogel; white bar is $10 \mu \mathrm{m}$.

with $\sim 20$ and $\sim 10 \%$ mass loss, respectively, after $1 \mathrm{~h}$. After 48 $\mathrm{h}$, an estimated $66 \%$ of the $9 \% \mathrm{w} / \mathrm{v}$ hydrogel had eroded, whereas only $50 \%$ of the $18 \% \mathrm{w} / \mathrm{v}$ hydrogel had dissolved. These results demonstrate that the lifetime of the material can be prolonged by increasing the percentage of the hydrogel. This is likely due to the increase in the number of physical crosslinks able to be formed between the polymers as well as potential entanglements. Our resulting erosion profiles are similar to those of other protein-based hydrogels. ${ }^{120-122}$ To determine the erosion of the hydrogel under proteolytic conditions, 9 and $18 \% \mathrm{w} / \mathrm{v}$ hydrogels were subjected to collagenase activity, and their resulting erosion profiles can also be seen in Figure 7. As predicted, considering the proteolysis studies of CCLP3 polymer, both hydrogels experienced a considerable increase in erosion rate and percent mass loss upon the addition of protease. After $48 \mathrm{~h}, \sim 75$ and $\sim 67 \%$ mass loss was determined for the 9 and $18 \% \mathrm{w} / \mathrm{v}$ hydrogels, respectively. This increase in erosion is the direct result of collagenase activity and demonstrates that this hydrogel material would be capable of disassembling at an accelerated rate if applied in the extracellular matrix, which is continually remodeled by endogenous collagenases.

Morphology of Hydrogels. Figure 8 shows micrographs of a $9 \%$ hydrogel sample prepared by lyophilization and imaged using SEM. Compared to the traditional method of SEM sample preparation, lyophilization has been reported to have a minimized effect on the morphology of the hydrogel and is commonly employed for morphology studies. ${ }^{123,124}$ The resulting micrographs reveal an interconnected network with a high degree of structural homogeneity between the surface (Figure 8A,B) and interior (Figure 8C) of the hydrogel, as well as a uniform spatial distribution of pores. Additionally, the interwoven network possesses a distribution of pore sizes normally ranging between 1 and $7 \mu \mathrm{m}$ (Figure $8 \mathrm{~B}$ ). These SEM results indicate that the material possesses extensive external and internal porosity and would be permeable to interstitial fluid, which contains extracellular components such as calcium ions, proteases, metabolites, and growth factors. ${ }^{125}$

Microrheology of Polymers and Hydrogels. We began our microrheological studies by first investigating the properties of each of the polymeric constituents of the hydrogel. Figure 9 shows representative MSD curves for $1 \mu \mathrm{m}$ probes suspended in a series of individual polymer solutions of CCLP3 (3-28\% w/v) and PCLP3 (1-9\% w/v) as well as data from bovine serum albumin (BSA) solutions as a model globular protein. The selected ranges of polymer concentrations correspond to the concentrations of each polymer used to form $4-18 \%$ hydrogels in a $1: 1$ mole ratio in
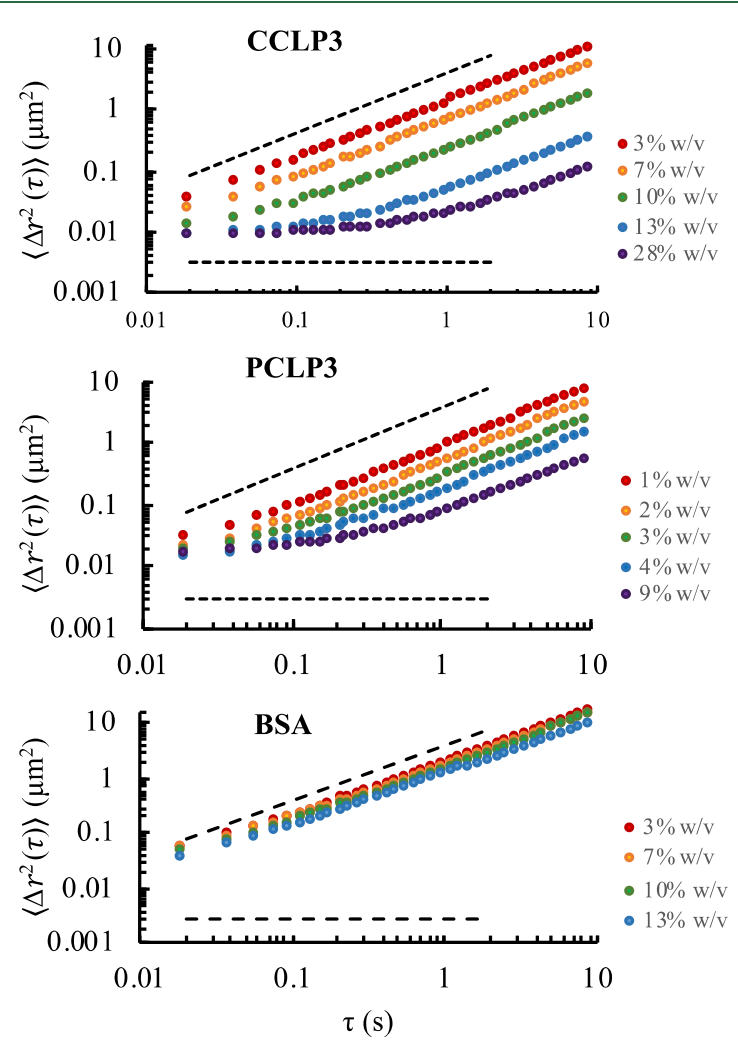

Figure 9. MSD plots were obtained for $1.0 \mu \mathrm{m}$ fluorescent spheres suspended in a series of concentrations of CCLP3 (A) and PCLP3 (B), as well as BSA (C) for comparison. Note that particle motion becomes increasingly subdiffusive as the concentrations of polymers increase, whereas particles exhibit normal diffusion in similar concentrations of BSA, a control with similar MW to CCLP3.

subsequent experiments. MPT results obtained for relatively dilute concentrations of CCLP3 $(c \leq 7 \%)$ and PCLP3 $(c \leq 2 \%$ $\mathrm{w} / \mathrm{v})$ revealed MSD values that increased linearly with lag time $\tau$ (slope $\alpha=0.94 \pm 0.01$ ) over the time observed (Figure $9 \mathrm{~A}, \mathrm{~B})$. The probe dynamics in these dilute polymeric solutions reflect simple diffusion, $\alpha \approx 1$, which indicates a predominantly viscous response of the suspensions of CCLP3 and PCLP3 in the lower range of polymer concentration. In higher concentrations of CCLP3 (7\% $<c \geq 13 \%)$ and PCLP3 (2\% $<c \geq 9 \%$, the mobility of the particles was increasingly constrained at short lag times $(\tau<0.5 \mathrm{~s})$, having MSDs with initial slopes of $\alpha=0.53 \pm 0.24$ and $\alpha=0.51 \pm 0.18$, respectively. The subdiffusion of probes within these polymeric solutions reflects a predominantly elastic response of the 
A

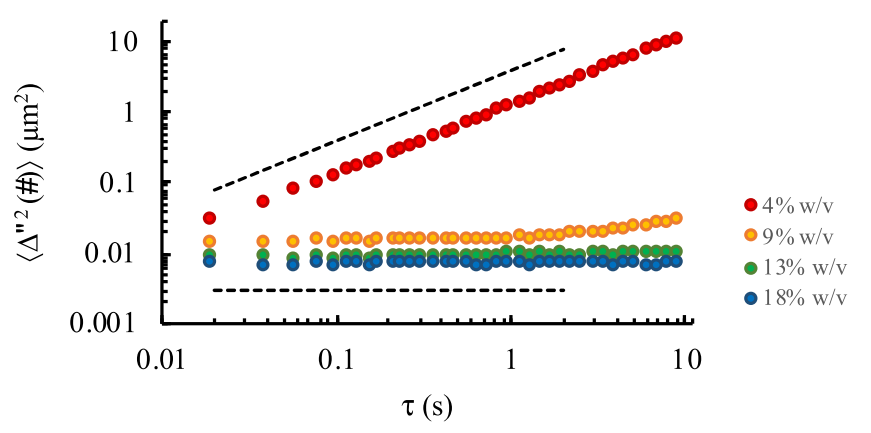

C

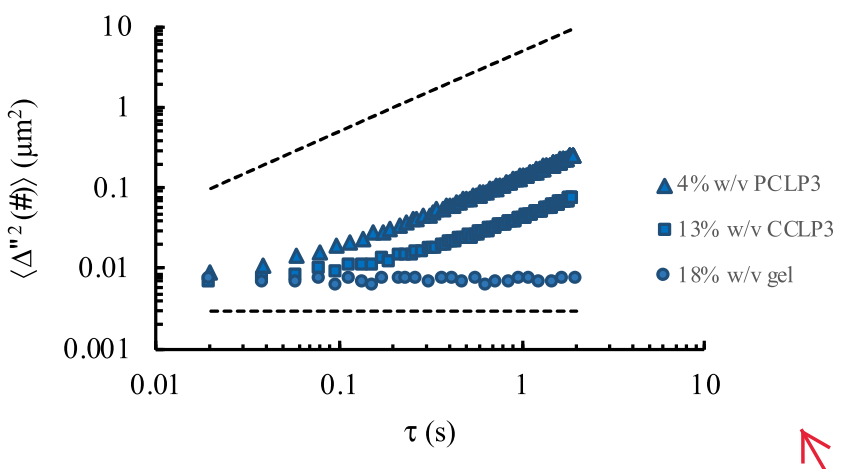

N
B
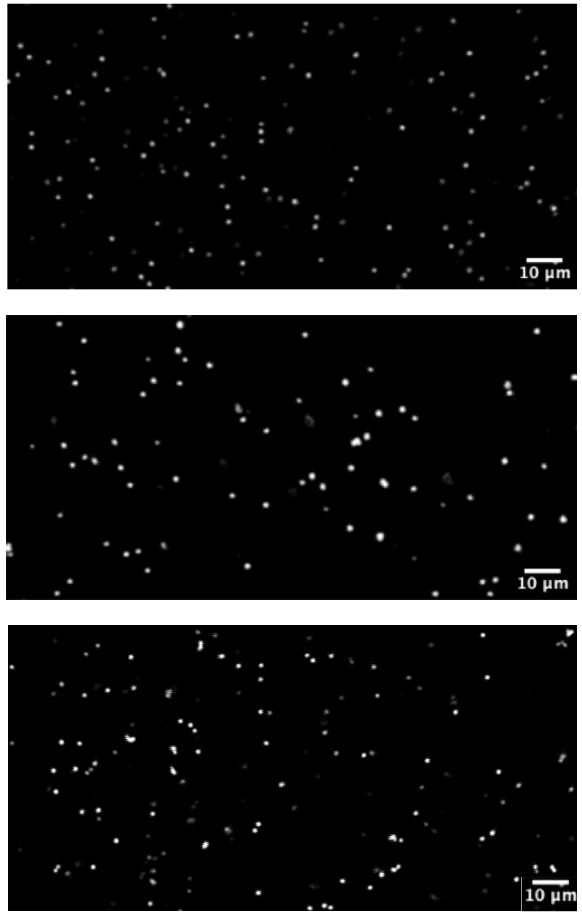

Figure 10. (A) Hydrogels (4-18\% w/v) were formed with embedded probes for MPT as previously described; gelation is dependent on the

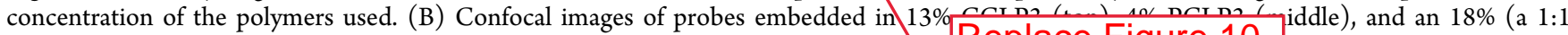
molar ratio of 13\% CCLP3 and 4\% PCLP3) hydrogel (bottom) are shown; little to no Replace Figure 10 hpiled MSD plot depicting MPT results for $18 \%$ hydrogel and individual polymer solutions (13\% CCLP3 and 4\% with revised. The was conducted using $1 \mu \mathrm{m}$ probes.

medium in higher polymer concentrations. However, at lag times greater than $0.5 \mathrm{~s}$, particle dynamics in these concentrated CCLP3 and PCLP3 solutions approached simple diffusion $(\alpha=0.92 \pm 0.05$ and $\alpha=0.94 \pm 0.05$, respectively). The sublinear scaling of MSD with $\tau,\left\langle\Delta r^{2}(\tau)\right\rangle \sim \tau^{\alpha<1}$, at higher concentrations is a common characteristic of complex viscoelastic fluids such as polymeric solutions, which can exhibit fibrillar entanglements and large-scale molecular motions on timescales as low as milliseconds. ${ }^{126}$ The fibrous nature of these protein polymers is further illustrated by directly comparing the corresponding MSD data with that of the globular protein BSA (Figure 9C), which showed no elastic response at similar concentrations. Finally, studies of $5 \mathrm{mM}$ CCLP3 (28\% w/v) and $5 \mathrm{mM}$ PCLP3 (9\% w/v) were performed, since these are the concentrations of polymers that are mixed to form a $18 \%$ hydrogel. For CCLP3 solutions at this high concentration, particle motion was subdiffusive $(\alpha=0.45)$ over the total time observed, whereas particles in $9 \%(5 \mathrm{mM})$ PCLP3 transitioned from slow to quick diffusion as lag time increased. Ultimately, these MPT results obtained for the polymer solutions confirm that the hydrogel components are fibrous in nature possessing elastic character and that polymer suspensions confer greater elasticity as concentrations increase due to the formation of transient entanglements.

For microrheological studies of the hydrogels, the two polymers were mixed in the presence of calcium to form 4$18 \% \mathrm{w} / \mathrm{v}$ solutions with $1.0 \mu \mathrm{m}$ tracer particles embedded, allowed to equilibrate for $30 \mathrm{~min}$, and then analyzed using MPT. Tracking results in Figure 10A show that in polymer mixtures a deleted in new

the time o version.

freely $(\alpha>0.96)$ over ymer concentration was increased to $9 \% \mathrm{w} / \mathrm{v}$, particie motion became highly restricted $(\Delta r \sim 200 \mathrm{~nm})$ at $\tau$ values less than $1 \mathrm{~s}$, but showed signs of slow diffusion $(\alpha>0.4)$ at longer lag times. Additionally, particles embedded in 13 and $18 \% \mathrm{w} / \mathrm{v}$ hydrogels appeared increasingly confined $(\Delta r \sim 110 \mathrm{~nm})$ with no indication of diffusion over the time observed. This observed elastic response is due to the formation of physical crosslinks between CCLP3 and PCLP3. Data in Figure 10B,C show direct comparisons of probe behavior in separate solutions of CCLP3 $(13 \% \mathrm{w} / \mathrm{v})$ and PCLP3 (4\% w/v), as well as the resulting $18 \%$ $\mathrm{w} / \mathrm{v}$ hydrogel in which the polymers were mixed at the same corresponding concentrations (equivalent to a 1:1 molar ratio). Figure 10B shows representative confocal microscopic images of the three probe-embedded samples. These images illustrate that there is little to no aggregation of beads in the polymer solutions and the hydrogel. In Figure 10C, the corresponding MSDs obtained by particle tracking demonstrate that when these polymers were mixed in an equimolar ratio, the resulting $18 \%$ hydrogel exhibited greater elasticity than the independent polymer solutions which comprise it due to the crosslinking between CCLP3 and PCLP3. Ultimately, these findings demonstrate that there is a critical concentration $(4 \%<c<9 \%)$ of polymer required to sufficiently facilitate the degree of crosslinking necessary for network formation. Once formed, the gel's microenvironment resembles that of a porous elastic solid and allows for slow diffusion of micron-sized particles at low concentrations, but increasingly restricts 
particle motion at higher polymer concentrations. Thus, these results are in agreement with the morphology studies presented above.

Probe Size Effects in Hydrogels. To accurately calculate shear moduli for a viscoelastic medium using MPT, the embedded particles must experience an identical microenvironment, or spatial continuum. Due to observed heterogeneities on the length scale probed $(\leq 1.0 \mu \mathrm{m})$ and, thus, a breakdown of the spatial continuum assumption, no bulk viscoelastic moduli could be determined for our hydrogel material. For closer comparison to the morphology data from SEM studies, the microstructure of the hydrogels was further investigated with $0.5 \mu \mathrm{m}$ probes embedded in $18 \% \mathrm{w} / \mathrm{v}$ hydrogels and tracked. The resulting radius-scaled MSDs for the tracers are shown in Figure 11. When scaled with the corresponding

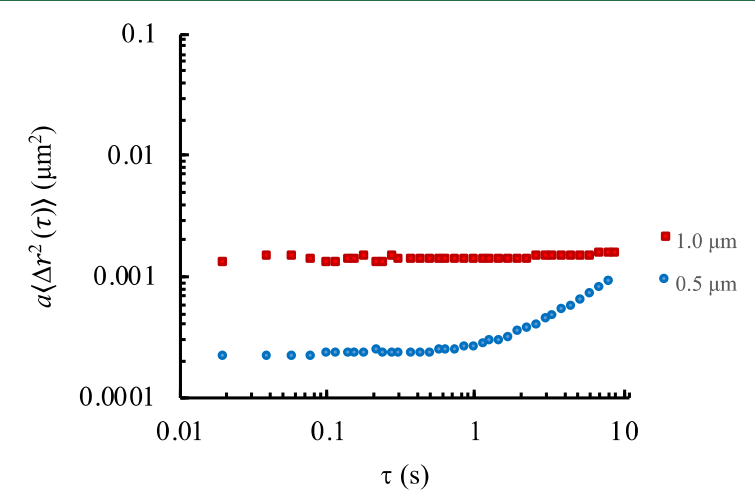

Figure 11. Probe size effects in hydrogels; $18 \% \mathrm{w} / \mathrm{v}$ hydrogels were prepared with either 0.5 or $1.0 \mu \mathrm{m}$ probes; submicron particles are less restricted by the hydrogel network and therefore diffuse more quickly.

radius, the MSD curves for different-sized probes should coincide if probes experience similar microenvironments. However, the MPT results obtained show that the larger 1.0 $\mu \mathrm{m}$ probes exhibited a constant MSD (slope $\alpha \approx 0$ ) over all lag times $\tau$ observed, whereas the particle dynamics for the smaller $0.5 \mu \mathrm{m}$ probes varied over different timescales, having a constant MSD $(\alpha \approx 0)$ for $\tau<1$ and exhibiting subdiffusion $(\alpha$ $=0.63)$ at $\tau>1$. This indicates that smaller nanoparticles can diffuse more rapidly through the viscous fluid component of the hydrogel, while large particles experience the elastic response of the copolymeric network over extended durations (albeit at varying degrees due to spatial heterogeneities). Again, these results agree with the morphology data obtained using SEM, which showed a microporous structure with pore size ranging between 1 and $7 \mu \mathrm{m}$. The ability to encapsulate microspheres is beneficial for in situ delivery applications, in which cargo-loaded microspheres are entrapped within a hydrogel and slowly released at a localized area to safely deliver drug or growth factors. ${ }^{127-129}$ There have been several reports of such "composite hydrogels" accomplishing long-term release of drugs such as nonsteroidal anti-inflammatory agents, ${ }^{130}$ chemotherapeutic agents, ${ }^{131,132}$ and antibiotics. ${ }^{133}$

In summary, CCLP3 and PCLP3 polymers are fibrous proteins that when mixed in the presence of calcium, selfassemble to form a matrix with a uniform spatial distribution of pores. This viscoelastic matrix encapsulates micron and submicron particles, such that larger particles are more constrained than smaller particles. The consistent morphology and the viscoelastic properties of our CaM-based hydrogel make it an appropriate scaffold for in situ drug delivery.

\section{CONCLUSIONS}

We have successfully developed a two-component, proteinbased hydrogel that is predicated on the calcium-stabilized interaction between CaM and CaM-binding peptide M13. Protein polymers were designed to contain three repeats of $\mathrm{CaM}$, or M13, with intervening degradable linker sequences. The genetically engineered proteins were bacterially expressed and purified using simple chromatographic methods. Spectroscopic studies demonstrate that CaM-based polymer CCLP3 reversibly binds PCLP3 in a calcium-dependent manner, which is a biologically relevant cue for extracellular applications, and self-assemble to form a soft porous network that would allow for the diffusion of small ions and small molecules. Gelation is dependent on the concentration of protein and is greatly attenuated when calcium is removed, resulting in the precipitation of PCLP3. This stabilizing effect of calcium is advantageous in vivo, where calcium is tightly regulated at a high concentration within the extracellular matrix. When exposed to endogenous collagenases, which are pervasive in disease processes involving inflammation, the polymers undergo targeted cleavage at the linker regions. In addition, erosion profiles reveal that collagenase activity increases the disassembly of the hydrogel. These studies indicate that this hydrogel system possesses appealing attributes that are conducive to biological applications.

\section{ASSOCIATED CONTENT}

\section{SI Supporting Information}

The Supporting Information is available free of charge at https://pubs.acs.org/doi/10.1021/acs.biomac.0c00043.

Amino acid sequences of CCLP3 and PCLP3 (Figure S1); MSDs of aqueous glycerol (Figure S2); viscosities of aqueous glycerol (Figure S3) (PDF)

\section{AUTHOR INFORMATION}

\section{Corresponding Author}

Susan Pedigo - Department of Chemistry and Biochemistry, University of Mississippi, University, Mississippi 38677, United States; orcid.org/0000-0003-0431-7024;

Email: spedigo@olemiss.edu

\section{Authors}

Christopher S. Fox - Department of Chemistry and Biochemistry, University of Mississippi, University, Mississippi 38677, United States; o orcid.org/0000-0002-9395-2486

Hunter A. Berry - Department of Chemistry and Biochemistry, University of Mississippi, University, Mississippi 38677, United States

Complete contact information is available at: https://pubs.acs.org/10.1021/acs.biomac.0c00043

\section{Notes}

The authors declare no competing financial interest.

\section{ACKNOWLEDGMENTS}

The SEM studies were funded in part by NSF MRI award number 1726880. C.S.F. was funded in part by Dept. of Education GAANN award \#P200A120046. H.A.B. was funded in part by a grant from the Sally MacDonald Barksdale Honors 
College at the University of Mississippi. The SEM studies were Hvdrogels with High Modulus for Bone Tissue Engineering. funded in part by NSF MRI award 1726880. 1726880. Ashley Williams contributed o. e1900142.

\section{REFERENCES} technical assistance to the viscosity measurements of glycerol.

(1) Wichterle, O.; Lim, D. Hydrophilic gels for biologicar use. rvarurc 1960, 185, 117-118.

(2) Gupta, A.; Kowalczuk, M.; Heaselgrave, W.; Britlan, S. T.; Martin, C.; Radecka, I. The production and application of hydrogels for wound management: A review. Eur. Polym. J. 2019, 111, 134-151.

(3) Hamedi, H.; Moradi, S.; Hudson, S. M.; Tonelli, A. E. Chitosan based hydrogels and their applications for drug delivery in wound dressings: A review. Carbohydr. Polym. 2018, 199, 445-460.

(4) Li, J.; Mooney, D. J. Designing hydrogels for controlled drug delivery. Nat. Rev. Mater. 2016, 1, No. 16071.

(5) Wu, H.; Liu, S.; Xiao, L.; Dong, X.; Lu, Q.; Kaplan, D. L. Injectable and $\mathrm{pH}$-Responsive Silk Nanofiber Hydrogels for Sustained Anticancer Drug Delivery. ACS Appl. Mater. Interfaces 2016, 8, 17118-17126.

(6) Dimatteo, R.; Darling, N. J.; Segura, T. In situ forming injectable hydrogels for drug delivery and wound repair. Adv. Drug Delivery Rev. 2018, 127, 167-184.

(7) Tang, J. D.; Mura, C.; Lampe, K. J. Stimuli-Responsive, Pentapeptide, Nanofiber Hydrogel for Tissue Engineering. J. Am. Chem. Soc. 2019, 141, 4886-4899.

(8) Guo, J. L.; Kim, Y. S.; Xie, V. Y.; Smith, B. T.; Watson, E.; Lam, J.; Pearce, H. A.; Engel, P. S.; Mikos, A. G. Modular, tissue-specific, and biodegradable hydrogel cross-linkers for tissue engineering. Sci. Adv. 2019, 5, No. eaaw7396.

(9) Zhang, Y.; Yu, J.; Ren, K.; Zuo, J.; Ding, J.; Chen, X. Thermosensitive Hydrogels as Scaffolds for Cartilage Tissue Engineering. Biomacromolecules 2019, 20, 1478-1492.

(10) Liu, M.; Zeng, X.; Ma, C.; Yi, H.; Ali, Z.; Mou, X.; Li, S.; Deng, Y.; $\mathrm{He}, \mathrm{N}$. Injectable hydrogels for cartilage and bone tissue engineering. Bone Res. 2017, 5, No. 17014.

(11) Zhao, X.; Lang, Q.; Yildirimer, L.; Lin, Z. Y.; Cui, W.; Annabi, N.; Ng, K. W.; Dokmeci, M. R.; Ghaemmaghami, A. M.; Khademhosseini, A. Photocrosslinkable Gelatin Hydrogel for Epidermal Tissue Engineering. Adv. Healthcare Mater. 2016, 5, $108-118$.

(12) Li, F.; Lyu, D.; Liu, S.; Guo, W. DNA Hydrogels and Microgels for Biosensing and Biomedical Applications. Adv. Mater. 2020, 32, No. e1806538.

(13) Akolpoglu, M. B.; Bozuyuk, U.; Erkoc, P.; Kizilel, S. Biosensing-Drug Delivery Systems for In Vivo Applications. In Advanced Biosensors for Health Care Applications; Inamuddin, R. K.; Mohammad, A.; Asiri, A. M., Eds.; Elsevier: Saudi Arabia, 2019; pp 249-262.

(14) Mao, X.; Chen, G.; Wang, Z.; Zhang, Y.; Zhu, X.; Li, G. Surface-immobilized and self-shaped DNA hydrogels and their application in biosensing. Chem. Sci. 2018, 9, 811-818.

(15) Lian, M.; Chen, X.; Lu, Y.; Yang, W. Self-Assembled Peptide Hydrogel as a Smart Biointerface for Enzyme-Based Electrochemical Biosensing and Cell Monitoring. ACS Appl. Mater. Interfaces 2016, 8, 25036-25042.

(16) Wu, J.; Li, P.; Dong, C.; Jiang, H.; Bin, X.; Gao, X.; Qin, M.; Wang, W.; Bin, C.; Cao, Y. Rationally designed synthetic protein hydrogels with predictable mechanical properties. Nat. Commun. 2018, 9, No. 620.

(17) Wollenberg, A. L.; O’Shea, T. M.; Kim, J. H.; Czechanski, A.; Reinholdt, L. G.; Sofroniew, M. V.; Deming, T. J. Injectable polypeptide hydrogels via methionine modification for neural stem cell delivery. Biomaterials 2018, 178, 527-545.

(18) Liu, H.; Cheng, Y.; Chen, J.; Chang, F.; Wang, J.; Ding, J.; Chen, $\mathrm{X}$. Component effect of stem cell-loaded thermosensitive polypeptide hydrogels on cartilage repair. Acta Biomater. 2018, 73, 103-111.

(19) Pal, P.; Nguyen, Q. C.; Benton, A. H.; Marquart, M. E.; Janorkar, A. V. Drug-Loaded Elastin-Like Polypeptide-Collagen
(21) Matricardi, P.; Di Meo, C.; Coviello, T.; Hennink, W. E.; Alhaique, F. Interpenetrating Polymer Networks polysaccharide hydrogels for drug delivery and tissue engineering. Adv. Drug Delivery Rev. 2013, 65, 1172-1187.

(22) Liu, H.; Li, C.; Wang, B.; Sui, X. L.; Wang, L.; Yan, X.; Xu, H.; Zhang, L.; Zhong, Y.; Mao, Z. Self-healing and injectable polysaccharide hydrogels with tunable mechanical properties. Cellulose 2018, 25, 559-571.

(23) Sabbagh, F.; Muhamad, I. I.; Nazari, Z.; Mobini, P.; Taraghdari, S. B. From formulation of acrylamide-based hydrogels to their optimization for drug release using response surface methodology. Mater. Sci. Eng., C 2018, 92, 20-25.

(24) Bal, A.; Özkahraman, B.; Özbaş, Z. Preparation and characterization of $\mathrm{pH}$ responsive poly(methacrylic acid-acrylamideN-hydroxyethyl acrylamide) hydrogels for drug delivery systems. J. Appl. Polym. Sci. 2016, 133, No. 43226.

(25) Cao, Y.; Xiong, D.; Wang, K.; Niu, Y. Semi-degradable porous poly (vinyl alcohol) hydrogel scaffold for cartilage repair: Evaluation of the initial and cell-cultured tribological properties. J. Mech. Behav. Biomed. Mater. 2017, 68, 163-172.

(26) Orienti, I.; Trere, R.; Luppi, B.; Bigucci, F.; Cerchiara, T.; Zuccari, G.; Zecchi, V. Hydrogels formed by crosslinked poly(vinyl alcohol) as sustained drug delivery systems. Arch. Pharm. (Weinheim, Ger.) 2002, 335, 89-93.

(27) Shimizu, Y.; Putra, N. K.; Ohta, M. Reproduction method for dried biomodels composed of poly (vinyl alcohol) hydrogels. Sci. Rep. 2018, 8, No. 5754.

(28) Kim, J.; Kong, Y. P.; Niedzielski, S. M.; Singh, R. K.; Putnam, A. J.; Shikanov, A. Characterization of the crosslinking kinetics of multiarm poly(ethylene glycol) hydrogels formed via Michael-type addition. Soft Matter 2016, 12, 2076-2085.

(29) Kim, M.; Cha, C. Modulation of functional pendant chains within poly(ethylene glycol) hydrogels for refined control of protein release. Sci. Rep. 2018, 8, No. 4315.

(30) Kar, M.; Vernon Shih, Y. R.; Velez, D. O.; Cabrales, P.; Varghese, S. Poly(ethylene glycol) hydrogels with cell cleavable groups for autonomous cell delivery. Biomaterials 2016, 77, 186-197.

(31) Patil, S. B.; Inamdar, S. Z.; Reddy, K. R.; Raghu, A. V.; Soni, S. K.; Kulkarni, R. V. Novel biocompatible poly(acrylamide)-grafteddextran hydrogels: Synthesis, characterization and biomedical applications. J. Microbiol. Methods 2019, 159, 200-210.

(32) Fan, L.; Yang, H.; Yang, J.; Peng, M.; Hu, J. Preparation and characterization of chitosan/gelatin/PVA hydrogel for wound dressings. Carbohydr. Polym. 2016, 146, 427-434.

(33) Ibrahim, A. G.; Sayed, A. Z.; El-Wahab, H. A. Synthesis of Poly (Acrylamide-Graft-Chitosan) Hydrogel: Optimization of The Grafting Parameters and Swelling Studies. Am. J. Polym. Sci. Technol. 2019, $5,55-62$.

(34) Zhan, H.; Löwik, D. W. P. M. A Hybrid Peptide Amphiphile Fiber PEG Hydrogel Matrix for 3D Cell Culture. Adv. Funct. Mater. 2019, 29, No. 1808505 .

(35) Morris, A. H.; Lee, H.; Xing, H.; Stamer, D. K.; Tan, M.; Kyriakides, T. R. Tunable Hydrogels Derived from Genetically Engineered Extracellular Matrix Accelerate Diabetic Wound Healing. ACS Appl. Mater. Interfaces 2018, 10, 41892-41901.

(36) Chow, D.; Nunalee, M. L.; Lim, D. W.; Simnick, A. J.; Chilkoti, A. Peptide-based Biopolymers in Biomedicine and Biotechnology. Mater. Sci. Eng., R 2008, 62, 125-155.

(37) Ghandehari, H.; Hatefi, A. Advances in recombinant polymers for delivery of bioactive agents. Adv. Drug Delivery Rev. 2010, 62, 1403. 
(38) Frandsen, J. L.; Ghandehari, H. Recombinant protein-based polymers for advanced drug delivery. Chem. Soc. Rev. 2012, 41, 26962706.

(39) Haider, M.; Megeed, Z.; Ghandehari, H. Genetically engineered polymers: status and prospects for controlled release. J. Controlled Release 2004, 95, 1-26.

(40) Jonker, A. M.; Lowik, D. W. P. M.; van Hest, J. C. M. Peptideand Protein-based Hydrogels. Chem. Mater. 2012, 24, 759-773.

(41) Kopeček, J. Smart and genetically engineered biomaterials and drug delivery systems. Eur. J. Pharm. Sci. 2003, 20, 1-16.

(42) Wang, F.; Wang, Y.; Tian, C.; Xu, S.; Wang, R.; Hou, K.; Chen, W.; Zhao, P.; Yu, L.; Lu, Z.; Kaplan, D. L.; Xia, Q. Fabrication of the FGF1-functionalized sericin hydrogels with cell proliferation activity for biomedical application using genetically engineered Bombyx mori (B. mori) silk. Acta Biomater. 2018, 79, 239-252.

(43) Santos, M.; Serrano-Ducar, S.; Gonzalez-Valdivieso, J.; Vallejo, R.; Girotti, A.; Cuadrado, P.; Arias, F. J. Genetically Engineered Elastin-based Biomaterials for Biomedical Applications. Curr. Med. Chem. 2020, 26, 7117-7146.

(44) Brindha, J.; Kaushik, C.; Balamurali, M. M. Revisiting the insights and applications of protein engineered hydrogels. Mater. Sci. Eng. 2018, 95, 312-327.

(45) Cappello, J.; Crissman, J.; Dorman, M.; Mikolajczak, M.; Textor, G.; Marquet, M.; Ferrari, F. Genetic engineering of structural protein polymers. Biotechnol. Prog. 1990, 6, 198-202.

(46) Prince, J. T.; McGrath, K. P.; DiGirolamo, C. M.; Kaplan, D. L. Construction, cloning, and expression of synthetic genes encoding spider dragline silk. Biochemistry 1995, 34, 10879-10885.

(47) Beun, L. H.; Beaudoux, X. J.; Kleijn, J. M.; de Wolf, F. A.; Stuart, M. A. Self-assembly of silk-collagen-like triblock copolymers resembles a supramolecular living polymerization. ACS Nano 2012, 6, $133-140$.

(48) McPherson, D. T.; Morrow, C.; Minehan, D. S.; Wu, J.; Hunter, E.; Urry, D. W. Production and purification of a recombinant elastomeric polypeptide, G-(VPGVG)19-VPGV, from Escherichia coli. Biotechnol. Prog. 1992, 8, 347-352.

(49) Meyer, D. E.; Chilkoti, A. Genetically encoded synthesis of protein-based polymers with precisely specified molecular weight and sequence by recursive directional ligation: examples from the elastinlike polypeptide system. Biomacromolecules 2002, 3, 357-367.

(50) Nagarsekar, A.; Crissman, J.; Crissman, M.; Ferrari, F.; Cappello, J.; Ghandehari, H. Genetic engineering of stimuli-sensitive silkelastin-like protein block copolymers. Biomacromolecules 2003, 4, 602-607.

(51) Werten, M. W.; Teles, H.; Moers, A. P.; Wolbert, E. J.; Sprakel, J.; Eggink, G.; de Wolf, F. A. Precision gels from collagen-inspired triblock copolymers. Biomacromolecules 2009, 10, 1106-1113.

(52) Skrzeszewska, P.; Sprakel, J.; de Wolf, F.; Fokkink, R.; Cohen Stuart, M.; Gucht, J. Fracture and Self-Healing in a Well-Defined SelfAssembled Polymer Network. Macromolecules 2010, 43, 3542-3548.

(53) Petka, W. A.; Harden, J. L.; McGrath, K. P.; Wirtz, D.; Tirrell,

D. A. Reversible hydrogels from self-assembling artificial proteins. Science 1998, 281, 389-392.

(54) Hobson, K. F.; Housley, N. A.; Pedigo, S. Ligand-linked stability of mutants of the C-domain of calmodulin. Biophys. Chem. 2005, 114, 43-52.

(55) Moosavi-Movahedi, A. A.; Naderi, G. A.; Farzami, B. The denaturation behaviour of calmodulin in sodium n-dodecyl sulphate, dodecyl trimethyl ammonium bromide, guanidine hydrochloride and urea. Thermochim. Acta 1994, 239, 61-71.

(56) Tsalkova, T. N.; Privalov, P. L. Thermodynamic study of domain organization in troponin C and calmodulin. J. Mol. Biol. 1985, $181,533-544$.

(57) Barbato, G.; Ikura, M.; Kay, L. E.; Pastor, R. W.; Bax, A. Backbone dynamics of calmodulin studied by $15 \mathrm{~N}$ relaxation using inverse detected two-dimensional NMR spectroscopy: the central helix is flexible. Biochemistry 1992, 31, 5269-5278.
(58) Crouch, T. H.; Klee, C. B. Positive cooperative binding of calcium to bovine brain calmodulin. Biochemistry 1980, 19, 36923698.

(59) Linse, S.; Helmersson, A.; Forsen, S. Calcium binding to calmodulin and its globular domains. J. Biol. Chem. 1991, 266, 80508054.

(60) Pedigo, S.; Shea, M. A. Quantitative endoproteinase GluC footprinting of cooperative $\mathrm{Ca}^{2+}$ binding to calmodulin: proteolytic susceptibility of E31 and E87 indicates interdomain interactions. Biochemistry 1995, 34, 1179-1196.

(61) Crivici, A.; Ikura, M. Molecular and structural basis of target recognition by calmodulin. Annu. Rev. Biophys. Biomol. Struct. 1995, $24,85-116$.

(62) Hurwitz, S. Homeostatic control of plasma calcium concentration. Crit. Rev. Biochem. Mol. Biol. 1996, 31, 41-100.

(63) Breitwieser, G. E. Extracellular calcium as an integrator of tissue function. Int. J. Biochem. Cell Biol. 2008, 40, 1467-1480.

(64) Fogh-Andersen, N.; Altura, B. M.; Altura, B. T.; SiggaardAndersen, O. Composition of interstitial fluid. Clin. Chem. 1995, 41, $1522-1525$.

(65) Baird, G. S.; Zacharias, D. A.; Tsien, R. Y. Circular permutation and receptor insertion within green fluorescent proteins. Proc. Natl. Acad. Sci. U.S.A. 1999, 96, 11241-11246.

(66) Horikawa, K.; Yamada, Y.; Matsuda, T.; Kobayashi, K.; Hashimoto, M.; Matsu-ura, T.; Miyawaki, A.; Michikawa, T.; Mikoshiba, K.; Nagai, T. Spontaneous network activity visualized by ultrasensitive $\mathrm{Ca}^{2+}$ indicators, yellow Cameleon-Nano. Nat. Methods 2010, 7, 729-732.

(67) Miyawaki, A.; Llopis, J.; Heim, R.; McCaffery, J. M.; Adams, J. A.; Ikura, M.; Tsien, R. Y. Fluorescent indicators for $\mathrm{Ca}^{2+}$ based on green fluorescent proteins and calmodulin [see comments]. Nature 1997, 388, 882-887.

(68) Ehrick, J. D.; Deo, S. K.; Browning, T. W.; Bachas, L. G.; Madou, M. J.; Daunert, S. Genetically engineered protein in hydrogels tailors stimuli-responsive characteristics. Nat. Mater. 2005, 4, 298302.

(69) Murphy, W. L.; Dillmore, W. S.; Modica, J.; Mrksich, M. Dynamic hydrogels: translating a protein conformational change into macroscopic motion. Angew. Chem., Int. Ed. 2007, 46, 3066-3069.

(70) Sui, Z.; King, W. J.; Murphy, W. L. Dynamic Materials Based on a Protein Conformational Change. Adv. Mater. 2007, 19, 33773380.

(71) Sui, Z.; King, W. J.; Murphy, W. L. Protein-Based Hydrogels with Tunable Dynamic Responses. Adv. Funct. Mater. 2008, 18, 1824-1831.

(72) King, W. J.; Mohammed, J. S.; Murphy, W. L. Modulating Growth Factor Release from Hydrogels via a Protein Conformational Change. Soft Matter 2009, 5, 2399-2406.

(73) King, W. J.; Pytel, N. J.; Ng, K.; Murphy, W. L. Triggered drug release from dynamic microspheres via a protein conformational change. Macromol. Biosci. 2010, 10, 580-584.

(74) Topp, S.; Prasad, V.; Ciani, G. C.; Weeks, E. R.; Gallivan, J. P. A Genetic Toolbox for Creating Reversible $\mathrm{Ca}^{2+}$-Sensitive Materials. J. Am. Chem. Soc. 2006, 128, 13994-13995.

(75) Kim, B.; Chilkoti, A. Allosteric actuation of inverse phase transition of a stimulus-responsive fusion polypeptide by ligand binding. J. Am. Chem. Soc. 2008, 130, 17867-17873.

(76) Beech, B. M.; McAteer, K.; Squier, T.; Baird, C.; Xiong, Y. Physical Properties of a Calmodulin Hydrogel as a Scaffold for Protein Immobilization. Biophys. J. 2013, 104, 180a-181a.

(77) Nagarsekar, A.; Ghandehari, H. Genetically engineered polymers for drug delivery. J. Drug Targeting 1999, 7, 11-32.

(78) Shen, W.; Zhang, K.; Kornfield, J. A.; Tirrell, D. A. Tuning the erosion rate of artificial protein hydrogels through control of network topology. Nat. Mater. 2006, 5, 153-158.

(79) McDaniel, J. R.; Bhattacharyya, J.; Vargo, K. B.; Hassouneh, W.; Hammer, D. A.; Chilkoti, A. Self-assembly of thermally responsive nanoparticles of a genetically encoded peptide polymer by drug conjugation. Angew. Chem., Int. Ed. 2013, 52, 1683-1687. 
(80) Creel, H. S.; Fournier, M. J.; Mason, T. L.; Tirrell, D. A. Genetically directed syntheses of new polymeric materials: efficient expression of a monodisperse copolypeptide containing fourteen tandemly repeated-(AlaGly) 4ProGluGly-elements. Macromolecules 1991, 24, 1213-1214.

(81) McGrath, K. P.; Fournier, M. J.; Mason, T. L.; Tirrell, D. A. Genetically directed syntheses of new polymeric materials. Expression of artificial genes encoding proteins with repeating-(AlaGly) 3ProGluGly-elements. J. Am. Chem. Soc. 1992, 114, 727-733.

(82) Shamji, M. F.; Betre, H.; Kraus, V. B.; Chen, J.; Chilkoti, A.; Pichika, R.; Masuda, K.; Setton, L. A. Development and characterization of a fusion protein between thermally responsive elastin-like polypeptide and interleukin-1 receptor antagonist: Sustained release of a local antiinflammatory therapeutic. Arthritis Rheum. 2007, 56, $3650-3661$.

(83) Urry, D. W. Physical chemistry of biological free energy transduction as demonstrated by elastic protein-based polymers. J. Phys. Chem. B 1997, 101, 11007-11028.

(84) Manicone, A. M.; McGuire, J. K. Matrix metalloproteinases as modulators of inflammation. Semin. Cell Dev. Biol. 2008, 19, 34-41.

(85) Parks, W. C.; Wilson, C. L.; Lopez-Boado, Y. S. Matrix metalloproteinases as modulators of inflammation and innate immunity. Nat. Rev. Immunol. 2004, 4, 617-629.

(86) Nathan, C. Points of control in inflammation. Nature 2002, $420,846-852$.

(87) Kazantseva, M. G.; Hung, N. A.; Highton, J.; Hessian, P. A. MMP expression in rheumatoid inflammation: the rs11568818 polymorphism is associated with MMP-7 expression at an extraarticular site. Genes Immun. 2013, 14, 162-169.

(88) Overall, C. M.; Kleifeld, O. Towards third generation matrix metalloproteinase inhibitors for cancer therapy. Br. J. Cancer 2006, 94, 941-946.

(89) Overall, C. M.; Dean, R. A. Degradomics: systems biology of the protease web. Pleiotropic roles of MMPs in cancer. Cancer Metastasis Rev. 2006, 25, 69-75.

(90) Cox, J. H.; Overall, C. M. Cytokine substrates: MMP regulation of inflammatory signaling molecules. In The Cancer Degradome: Proteases and Cancer Biology 2009th Edition; Edwards, D.; HoyerHansen, G.; Blasi, F.; Sloane, B. F., Eds.; Springer: New York, NY, 2008; pp 519-539.

(91) Egeblad, M.; Werb, Z. New functions for the matrix metalloproteinases in cancer progression. Nat. Rev. Cancer 2002, 2, 161-174.

(92) McCawley, L. J.; Matrisian, L. M. Matrix metalloproteinases: they're not just for matrix anymore! Curr. Opin. Cell Biol. 2001, 13, $534-540$.

(93) Prasad, A.; Pedigo, S. Calcium-dependent Stability Studies of Domains 1 and 2 of Epithelial Cadherin. Biochemistry 2005, 44, 13692-13701.

(94) Putkey, J. A.; Slaughter, G. R.; Means, A. R. Bacterial expression and characterization of proteins derived from the chicken calmodulin cDNA and a calmodulin processed gene. J. Biol. Chem. 1985, 260, 4704-4712.

(95) Gill, S. C.; von Hippel, P. H. Calculation of Protein Extinction Coefficients from Amino Acid Sequence Data. Anal. Biochem. 1989, 182, 319-326.

(96) Prasad, A.; Zhao, H.; Rutherford, J. M.; Housley, N. A.; Nichols, C.; Pedigo, S. Effect of linker segments upon the stability of Epithelial-Cadherin Domain 2. Proteins 2006, 62, 111-121.

(97) Xia, Q.; Xiao, H.; Pan, Y.; Wang, L. Microrheology, advances in methods and insights. Adv. Colloid Interface Sci. 2018, 257, 71-85.

(98) Crocker, J. C.; Grier, D. G. Methods of Digital Video Microscopy for Colloidal Studies. J. Colloid Interface Sci. 1996, 179, 298-310.

(99) Ferry, J. D. Viscoelastic Properties of Polymers; 3rd ed.; Wiley: New York, 1980.

(100) Mason, T. G. Estimating the viscoelastic moduli of complex fluids using the generalized Stokes-Einstein equation. Rheol. Acta 2000, 39, 371-378.
(101) Mason, T. G.; Lacasse, M.-D.; Grest, G. S.; Levine, D.; Bibette, J.; Weitz, D. A. Osmotic pressure and viscoelastic shear moduli of concentrated emulsions. Phys. Rev. E 1997, 56, 3150.

(102) Mason, T. G.; Weitz, D. A. Optical measurements of frequency-dependent linear viscoelastic moduli of complex fluids. Phys. Rev. Lett. 1995, 74, 1250-1253.

(103) Dasgupta, B. R.; Tee, S.-Y.; Crocker, J. C.; Frisken, B. J.; Weitz, D. A. Microrheology of polyethylene oxide using diffusing wave spectroscopy and single scattering. Phys. Rev. E 2002, 65, No. 051505.

(104) Dasgupta, B. R.; Weitz, D. A. Microrheology of cross-linked polyacrylamide networks. Phys. Rev. E 2005, 71, No. 021504.

(105) Klee, C. B. Conformational transition accompanying the binding of $\mathrm{Ca} 2+$ to the protein activator of $3^{\prime}, 5^{\prime}$-cyclic adenosine monophosphate phosphodiesterase. Biochemistry 1977, 16, 10171024.

(106) Klevit, R. E.; Blumenthal, D. K.; Wemmer, D. E.; Krebs, E. G. Interaction of calmodulin and a calmodulin-binding peptide from myosin light chain kinase: major spectral changes in both occur as the result of complex formation. Biochemistry 1985, 24, 8152-8157.

(107) Greenfield, N.; Fasman, G. D. Computed circular dichroism spectra for the evaluation of protein conformation. Biochemistry 1969, $8,4108-4116$.

(108) Klevit, R. E. Spectroscopic analyses of calmodulin and its interactions. Methods Enzymol. 1983, 102, 82-104.

(109) Patterson, J.; Hubbell, J. A. Enhanced proteolytic degradation of molecularly engineered PEG hydrogels in response to MMP-1 and MMP-2. Biomaterials 2010, 31, 7836-7845.

(110) Knäuper, V.; Lopez-Otin, C.; Smith, B.; Knight, G.; Murphy, G. Biochemical characterization of human collagenase-3. J. Biol. Chem. 1996, 271, 1544-1550.

(111) Vaalamo, M.; Mattila, L.; Johansson, N.; Kariniemi, A. L.; Karjalainen-Lindsberg, M. L.; Kahari, V. M.; Saarialho-Kere, U. Distinct populations of stromal cells express collagenase-3 (MMP-13) and collagenase-1 (MMP-1) in chronic ulcers but not in normally healing wounds. J. Invest. Dermatol. 1997, 109, 96-101.

(112) Ståhle-Bäckdahl, M.; Sandstedt, B.; Bruce, K.; Lindhal, A.; Jimenez, M. G.; Vega, J. A.; Lopez-Otin, C. Collagenase-3 (MMP-13) is expressed during human fetal ossification and re-expressed in postnatal bone remodelling and in rheumatoid arthritis. Lab. Invest. 1997, 76, 717-728.

(113) Zitka, O.; Kukacka, J.; Krizkova, S.; Huska, D.; Adam, V.; Masarik, M.; Prusa, R.; Kizek, R. Matrix metalloproteinases. Curr. Med. Chem. 2010, 17, 3751-3768.

(114) Menkin, V.; Warner, C. R. Studies on Inflammation: XIII. Carbohydrate Metabolism, Local Acidosis, and the Cytological Picture in Inflammation. Am. J. Pathol. 1937, 13, 25-44.

(115) van Kempen, L. C.; de Visser, K. E.; Coussens, L. M. Inflammation, proteases and cancer. Eur. J. Cancer 2006, 42, 728734.

(116) El Kebir, D.; de Oliveira Lima Dos Santos, E.; Mansouri, S.; Sekheri, M.; Filep, J. G. Mild acidosis delays neutrophil apoptosis via multiple signaling pathways and acts in concert with inflammatory mediators. J. Leukocyte Biol. 2017, 102, 1389-1400.

(117) Bond, M. D.; Van Wart, H. E. Purification and separation of individual collagenases of Clostridium histolyticum using red dye ligand chromatography. Biochemistry 1984, 23, 3077-3085.

(118) Patterson, G. H.; Knobel, S. M.; Sharif, W. D.; Kain, S. R.; Piston, D. W. Use of the green fluorescent protein and its mutants in quantitative fluorescence microscopy. Biophys. J. 1997, 73, 27822790.

(119) Sillén, L. G.; Martell, A. E. Stability Constants of Metal-Ion Complexes;, Vol. Supplement No1 to Special Publication No 17, Special Publication No. 25, 3rd ed.; The Chemical Society: Burlington House, London, 1971.

(120) Lu, H. D.; Charati, M. B.; Kim, I. L.; Burdick, J. A. Injectable shear-thinning hydrogels engineered with a self-assembling Dock-andLock mechanism. Biomaterials 2012, 33, 2145-2153. 
(121) Han, S.; Ham, T. R.; Haque, S.; Sparks, J. L.; Saul, J. M. Alkylation of human hair keratin for tunable hydrogel erosion and drug delivery in tissue engineering applications. Acta Biomater. 2015, 23, 201-213.

(122) Ham, T. R.; Lee, R. T.; Han, S.; Haque, S.; Vodovotz, Y.; Gu, J.; Burnett, L. R.; Tomblyn, S.; Saul, J. M. Tunable Keratin Hydrogels for Controlled Erosion and Growth Factor Delivery. Biomacromolecules 2016, 17, 225-236.

(123) McGrath, J. L.; Hartwig, J. H.; Kuo, S. C. The mechanics of Factin microenvironments depend on the chemistry of probing surfaces. Biophys. J. 2000, 79, 3258-3266.

(124) Ma, X.; Sun, X.; Hargrove, D.; Chen, J.; Song, D.; Dong, Q.; Lu, X.; Fan, T. H.; Fu, Y.; Lei, Y. A Biocompatible and Biodegradable Protein Hydrogel with Green and Red Autofluorescence: Preparation, Characterization and In Vivo Biodegradation Tracking and Modeling. Sci. Rep. 2016, 6, No. 19370.

(125) Frantz, C.; Stewart, K. M.; Weaver, V. M. The extracellular matrix at a glance. J. Cell Sci. 2010, 123, 4195-4200.

(126) Sunthar, P. Polymer Rheology. In Rheology of Complex Fluids; Krishnan, J. M.; Deshpande, A. P.; Kumar, P. B. S., Eds.; Springer: New York, 2010; pp 171-191.

(127) Constantin, M.; Bucatariu, S. M.; Doroftei, F.; Fundueanu, G. Smart composite materials based on chitosan microspheres embedded in thermosensitive hydrogel for controlled delivery of drugs. Carbohydr. Polym. 2017, 157, 493-502.

(128) Chen, D.; Zhang, C.; Huo, H.; Ji, C.; Sun, M.; Nie, L. Injectable temperature-sensitive hydrogel with VEGF loaded microspheres for vascularization and bone regeneration of femoral head necrosis. Mater. Lett. 2018, 229, 138-141.

(129) Tang, Y.; Du, Y.; Li, Y.; Wang, X.; Hu, X. A thermosensitive chitosan/poly(vinyl alcohol) hydrogel containing hydroxyapatite for protein delivery. J. Biomed. Mater. Res. 2009, 91A, 953-963.

(130) Joung, Y. K.; Choi, J. H.; Park, K. M.; Park, K. D. PLGA microparticle-embedded thermosensitive hydrogels for sustained release of hydrophobic drugs. Biomed. Mater. 2007, 2, 269-273.

(131) Ranganath, S. H.; Kee, I.; Krantz, W. B.; Chow, P. K.; Wang, C. H. Hydrogel matrix entrapping PLGA-paclitaxel microspheres: drug delivery with near zero-order release and implantability advantages for malignant brain tumour chemotherapy. Pharm. Res. 2009, 26, 2101-2114.

(132) Ranganath, S. H.; Fu, Y.; Arifin, D. Y.; Kee, I.; Zheng, L.; Lee, H. S.; Chow, P. K.; Wang, C. H. The use of submicron/nanoscale PLGA implants to deliver paclitaxel with enhanced pharmacokinetics and therapeutic efficacy in intracranial glioblastoma in mice. Biomaterials 2010, 31, 5199-5207.

(133) Liu, W.-F.; Kang, C.-Z.; Kong, M.; Li, Y.; Su, S.; Yi, A.; Cheng, X.-J.; Chen, X.-G. Controlled release behaviors of chitosan $/ \alpha, \beta$ glycerophosphate thermo-sensitive hydrogels. Front. Mater. Sci. 2012, $6,250-258$.

\section{NOTE ADDED AFTER ASAP PUBLICATION}

Due to a production error, this paper was published ASAP on April 22, 2020, with the incorrect versions of the TOC/ abstract graphic and Scheme 1. The corrected version was reposted on April 29, 2020.

2020. A second

post ASAP was completed on May

27,2020 , to replace Figure 10 and update the Acknowledgments section. 